\title{
Preparation of Foam Dressings Based on Gelatin, Hyaluronic Acid, and Carboxymethyl Chitosan Containing Fibroblast Growth Factor-7 for Dermal Regeneration
}

\author{
Longhao Jin ${ }^{1,+}$, Sun-Jung Yoon ${ }^{2,+}$, Dae Hoon Lee ${ }^{3}$, Yun Chang Pyun ${ }^{3}$, Woo Youp Kim ${ }^{3}$, Ju Hwa Lee ${ }^{3}$, \\ Gilson Khang ${ }^{3}\left(\mathbb{D}\right.$, Heung Jae Chun ${ }^{4,5}$ id and Dae Hyeok Yang ${ }^{5, *(D)}$
}

Citation: Jin, L.; Yoon, S.-J.; Lee, D.H.; Pyun, Y.C.; Kim, W.Y.; Lee, J.H.; Khang, G.; Chun, H.J.; Yang, D.H. Preparation of Foam Dressings Based on Gelatin, Hyaluronic Acid, and Carboxymethyl Chitosan Containing Fibroblast Growth Factor-7 for Dermal Regeneration. Polymers 2021, 13, 3279. https://doi.org/10.3390/ polym13193279

Academic Editors: Dimitrios Bikiaris and Nathanael Guigo

Received: 3 August 2021

Accepted: 17 September 2021

Published: 26 September 2021

Publisher's Note: MDPI stays neutra with regard to jurisdictional claims in published maps and institutional affiliations.

Copyright: (c) 2021 by the authors Licensee MDPI, Basel, Switzerland. This article is an open access article distributed under the terms and conditions of the Creative Commons Attribution (CC BY) license (https:/ / creativecommons.org/licenses/by/ $4.0 /)$.
1 Department of Orthopedic Surgery, Yanbian University Hospital, Yanji 133000, China; jlh0423@sina.com

2 Department of Orthopedic Surgery, Research Institute of Clinical Medicine of Jeonbuk National University, Biomedical Research Institute of Jeonbuk National University Hospital, Jeonbuk National University Medical School, Jeonju 54896, Korea; sunjungyoon@jbnu.ac.kr

3 Department of Bionanotechnology and Bioconvergence Engineering, Department of Polymer Nano Science and Technology, Jeonbuk National University, Jeonju 54896, Korea; ldh7149@jbnu.ac.kr (D.H.L.); letter95@jbnu.ac.kr (Y.C.P.); snail2684@jbnu.ac.kr (W.Y.K.); wnghkljh@gmail.com (J.H.L.); gskhang@jbnu.ac.kr (G.K.)

4 Department of Medical Life Sciences, College of Medicine, The Catholic University of Korea, Seoul 06591, Korea; chunhj@catholic.ac.kr

5 Institute of Cell and Tissue Engineering, College of Medicine, The Catholic University of Korea, Seoul 06591, Korea

* Correspondence: yangdh@catholic.ac.kr; Tel.: +82-2-2258-7497

+ These two authors contributed to this study equally.

Abstract: Wound recovery close to the function of the native skin is the goal of wound healing. In this study, we prepared foam dressings (FDs; 2-GHC-FD-1-9, 5-GHC-FD-1-9, and 10-GHC-FD-1-9) composed of various concentrations of gelatin, hyaluronic acid, and carboxymethyl chitosan, which are chemically interconnected through amide bond formation, for evaluating wound healing. Tensile and cell proliferation tests showed that 2-GHC-FD-1-9 are suitable for wound dressing. For further evaluation, three types of FDs, 2-GHC-FD-1, 2-GHC-FD-4, and 2-GHC-FD-8 were chosen. The results of animal intradermal reactivity, water vapor transmission rate, and absorption rate of the three FDs indicated that 2-GHC-FD-8 is the most appropriate scaffold for wound healing. For wound healing acceleration, various concentrations of fibroblast growth factor-7 (FGF-7) was soaked in 2-GHC-FD-8 (2-GHC-FD-8/F1-6) and evaluated by using scanning electron microscopy, cell proliferation, release behavior, and in vivo animal tests. The FDs showed interconnected porous structures, increased cell proliferation until $8.0 \times 10^{-11} \mathrm{M}$, controlled release with initial burst within $1 \mathrm{~h}$, and sustained release for $48 \mathrm{~h}$. The results of the animal test showed an appropriate concentration of FGF-7 for wound healing. In addition, 2-GHC-FD-8 is a suitable scaffold for wound healing. Therefore, we suggest that 2-GHC-FD-8/F3 is a useful wound dressing for accelerating wound healing.

Keywords: gelatin; hyaluronic acid; carboxymethyl chitosan; fibroblast growth factor-7 (FGF-7); wound healing

\section{Introduction}

Ideal wound healing involves the prevention of secondary infections and the minimization of scarring. It occurs in a moist environment as re-epithelialization is promoted in a wet wound, followed by a reduction of scar formation [1]. Applying dressing to wounds can accelerate healthy wound healing by protecting the wound from bacteria and supporting a moist environment [2]. Several types of wound dressings have been reported, such as foams, hydrogels, hydrocolloids, and films, for improving wound healing [2]. Among these dressings, foam is a valuable tool for protecting trauma, controlling exuding 
wounds, and minimizing discomfort and pain [3]. In addition, foam dressing can support a moist environment, cushion wounds from additional trauma, provide thermal insulation, and simply applied and removed from the wounds [3].

Wound dressings have been developed using natural and synthetic polymers or their combinations [4]. Characteristics not observed in synthetic polymers, but observed in naturally derived polymers are, for example, high biocompatibility, similarity to the extracellular matrix, and minimal immunological reactions [5,6]. These unique properties are required for wound dressings.

Gelatin has been clinically tested for wound healing applications among natural polymers because of its hemostatic properties, good biocompatibility, and controlled biodegradability [7]. Hyaluronic acid (HA), a non-sulfated glycosaminoglycan (GAG), is a primary component of the skin extracellular matrix $(\mathrm{ECM})$ and is related to inflammatory response, angiogenesis, and tissue regeneration; however, its confined cell adhesion and proliferation limit its application as a wound dressing [8]. Chitosan derivatives, such as carboxymethyl chitosan (CMCS), glycol chitosan, etc., has also been investigated as a wound dressing material because of its high biocompatibility, biodegradability, antimicrobial activity, nontoxicity, and moisturizing capacity $[9,10]$. These natural polymers have been widely investigated for biomedical applications [9-16].

In addition to biomaterials for wound dressings, growth factors in dressings can improve wound healing through the migration, proliferation, and differentiation of cells related to healing [17]. Fibroblast growth factor-7 (FGF-7) has essential functions during wound healing [18-20]; it stimulates the migration and multiplication of keratinocytes and improves re-epithelialization. However, when growth factors are exogenously applied to wounds, they have restricted clinical effectiveness due to low stability in vivo and limited absorption through the skin around wounds [17]. Therefore, biomaterials that control the efficacy of growth factors under exogenous conditions are required.

The goal of this study is to investigate the efficacy of foam dressings (FDs), composed of gelatin, HA, and CMCS containing FGF-7 on wound healing acceleration in vivo (Figure 1). To the best of my knowledge, this combination is the first study evaluating its wound healing acceleration using wound animal model; this study must be carried out for the development of advanced wound dressings. The surface morphology of the foam dressings (FDs) was characterized using scanning electron microscopy (SEM). The biocompatibility tests were evaluated by NIH/3T3 cell proliferation, intradermal reactivity, water vapor transmission rate (WVTR), and absorption rate. The incorporation of FGF-7 in FDs was investigated using Fourier transform infrared spectroscopy (FTIR). The release behavior of FGF-7 was evaluated using the Cell Counting Kit-8 (CCK-8) assay. Wound healing efficacy was evaluated using a skin incisional mouse model for the macroscopic observation of wounds and histological evaluation. 


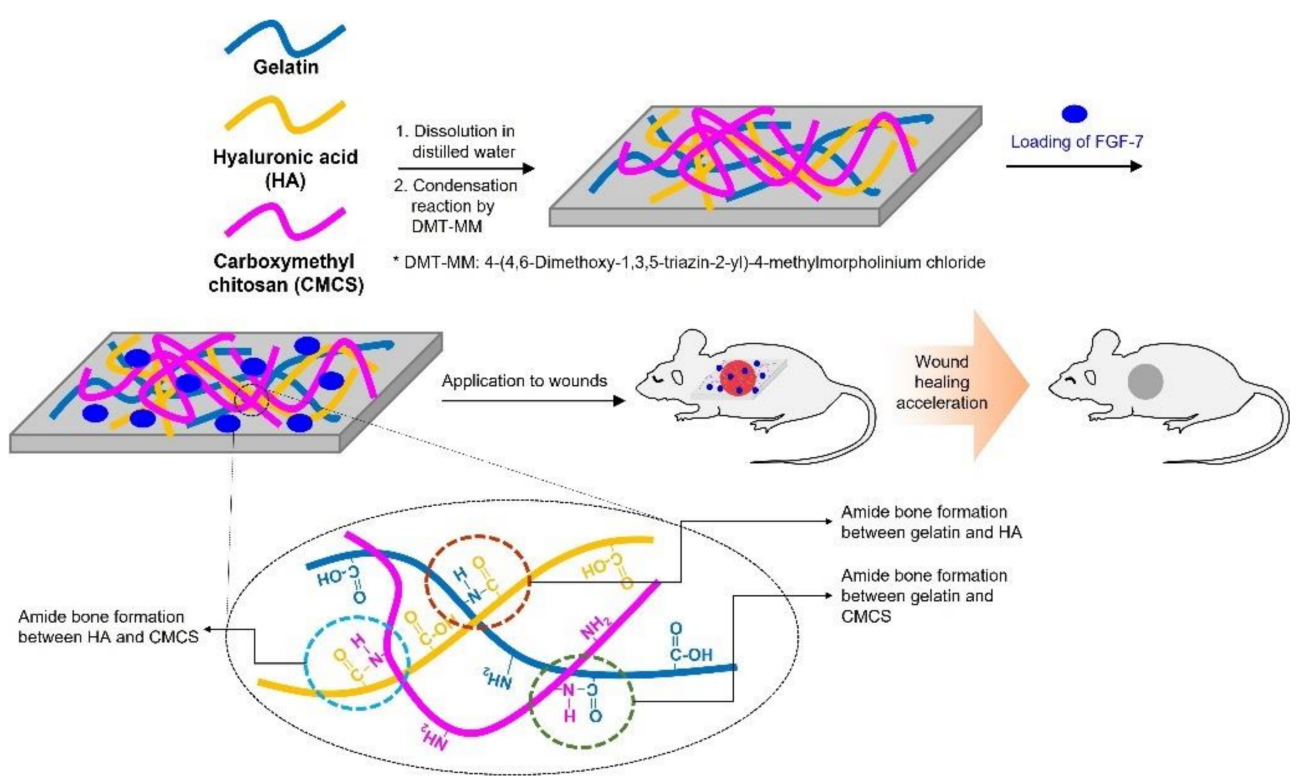

Figure 1. Schematic illustration of FDs made of gelatin, HA, and CMCS containing various concentrations of FGF-7 and amide bond formation among the polymers by condensation reaction. The amide bonds were formed by condensation reactions between the carboxylic group of gelatin and the amine group of HA, between the carboxylic group of HA and the amine group of gelatin, and between the carboxylic group of HA and the amine group of CMCS.

\section{Materials and Methods}

\subsection{Materials}

Gelatin (from porcine skin, gel strength 300, Type A), HA (from Streptococcus equi, Mw: 130,000-150,000 g/mol), and CMCS (deacetylation degree: 90\%) were purchased from Sigma-Aldrich, Inc. (St. Louis, MO, USA) and Santa Cruz Biotechnology, Inc. (Dallas, TX, USA), respectively. 4-(4,6-Dimethoxy-1,3,5-triazin-2-yl)-4methylmorpholinium chloride (DMT-MM, FUJIFILM Wako Pure Chemical Corp., Tokyo, Japan) was used for the condensation reaction among gelatin, HA, and CMCS. NI was obtained from the Korean Cell Line Bank (Seoul, Korea). Dulbecco's Modified Eagle Medium (DMEM), bovine serum, penicillin, and streptomycin were purchased from Thermo Fisher Scientific (Waltham, MA, USA). CCK-8 was supplied by Dojindo Molecular Technologies, Inc. (Rockville, MD, USA). Human KGF/FGF-7 Quantikine ${ }^{\circledR}$ ELISA Kit was purchased from R\&D Systems (Minneapolis, MN, USA). All organic chemicals were used for further purification.

\subsection{FDs Comprising Gelatin, CMCS, and HA (GHC-FDs)}

\subsubsection{Preparation}

The FDs were prepared by blending various concentrations of gelatin, HA, and CMCS (Table 1). Briefly, gelatin was dissolved in distilled water at $50{ }^{\circ} \mathrm{C}$. CMCS and HA were dissolved in distilled water at room temperature. Then, the three polymer solutions were mixed, poured into custom-made Teflon molds $(15 \mathrm{~cm} \times 15 \mathrm{~cm} \times 7 \mathrm{~cm})$, and maintained at room temperature until pudding. After lyophilization, the spongy FDs were reacted for $1 \mathrm{~d}$ using DMT-MM (2 g) as a condensation agent. Subsequently, the FDs were washed several times with distilled water to remove DMT-MM and lyophilized. The freeze-dried FDs were cut into $1 \mathrm{~cm} \times 1 \mathrm{~cm}$ pieces and sterilized using ethylene oxide gas. The surface morphologies were observed by using field emission SEM (FE-SEM; Inspect F; FEI, Hillsboro, OR, USA) at an accelerating voltage of $20 \mathrm{kV}$. Prior to this observations, all FDs were placed on aluminum stubs and coated with Pt by using an ion sputter-coater (Eiko IB-3, Eiko Engineering Co. Ltd., Ibaraki, Japan). The FDs were observed at 200×. 
Table 1. Amounts of gelatin, HA, CMCS, and DMT-MM used for hydrogelation. For hydrogelation, Specific concentrations of gelatin $(1,2,5$, and $10 w / v \%), \operatorname{HA}(1,5$, and $10 w / w \%)$, and CMCS (10, 50, and $100 w / w \%$ ) were used. As a condensation agent, $2 w / v \%$ of DMT-MM was used.

\begin{tabular}{|c|c|c|c|c|c|c|}
\hline \multicolumn{2}{|r|}{ FDs } & \multirow[t]{2}{*}{$\begin{array}{l}\text { Gelatin } \\
(w / v \%)\end{array}$} & \multirow[t]{2}{*}{$\begin{array}{c}\text { НА } \\
(w / w \%)\end{array}$} & \multirow{2}{*}{$\begin{array}{c}\begin{array}{c}\text { CMCS } \\
(w / w \%)\end{array} \\
10\end{array}$} & \multirow[t]{2}{*}{$\begin{array}{c}\text { DMT-MM } \\
(w / v \%)\end{array}$} & \multirow[t]{2}{*}{ Hydrogelation } \\
\hline \multirow{9}{*}{ 1- } & GHC-1 & & & & & \\
\hline & GHC-2 & \multirow{8}{*}{1} & \multirow[t]{3}{*}{1} & 50 & \multirow{8}{*}{2} & \multirow{8}{*}{$\times$} \\
\hline & GHC-3 & & & 100 & & \\
\hline & GHC-4 & & & 10 & & \\
\hline & GHC-5 & & 5 & 50 & & \\
\hline & GHC-6 & & & 100 & & \\
\hline & GHC-7 & & & 10 & & \\
\hline & GHC-8 & & 10 & 50 & & \\
\hline & GHC-9 & & & 100 & & \\
\hline \multirow{9}{*}{$2-$} & GHC-1 & \multirow{9}{*}{2} & \multirow{3}{*}{1} & 10 & & \multirow{9}{*}{$\mathrm{O}$} \\
\hline & GHC-2 & & & 50 & & \\
\hline & GHC-3 & & & 100 & & \\
\hline & GHC-4 & & & 10 & & \\
\hline & GHC-5 & & 5 & 50 & 2 & \\
\hline & GHC-6 & & & 100 & & \\
\hline & GHC-7 & & \multirow{3}{*}{10} & 10 & & \\
\hline & GHC-8 & & & 50 & & \\
\hline & GHC-9 & & & 100 & & \\
\hline \multirow{9}{*}{$5-$} & GHC-1 & & \multirow{4}{*}{1} & 10 & & \multirow{9}{*}{$\mathrm{O}$} \\
\hline & GHC-2 & & & 50 & & \\
\hline & GHC-3 & & & 100 & & \\
\hline & GHC-4 & & & 10 & & \\
\hline & GHC-5 & 5 & 5 & 50 & 2 & \\
\hline & GHC-6 & & & 100 & & \\
\hline & GHC-7 & & \multirow{3}{*}{10} & 10 & & \\
\hline & GHC-8 & & & 50 & & \\
\hline & GHC-9 & & & 100 & & \\
\hline \multirow{9}{*}{$10-$} & GHC-1 & & \multirow{3}{*}{1} & 10 & & \multirow{9}{*}{$\mathrm{O}$} \\
\hline & GHC-2 & & & 50 & & \\
\hline & GHC-3 & & & 100 & & \\
\hline & GHC-4 & & & 10 & & \\
\hline & GHC-5 & 10 & 5 & 50 & 2 & \\
\hline & GHC-6 & & \multirow{4}{*}{10} & 100 & & \\
\hline & GHC-7 & & & 10 & & \\
\hline & GHC-8 & & & 50 & & \\
\hline & GHC-9 & & & 100 & & \\
\hline
\end{tabular}

\subsubsection{NIH/3T3 Cell Proliferation and Live and Dead Assays}

$\mathrm{NIH} / 3 \mathrm{~T} 3$ cells $\left(5 \times 10^{6}\right.$ /each well) were seeded on the surface of hydrogelated FDs in Table 1 and cultured with a medium made of DMEM, 10\% bovine serum, $100 \mathrm{U} / \mathrm{L}$ penicillin, and $100 \mathrm{mg} / \mathrm{mL}$ streptomycin. The cells were incubated for 1, 3, 5, and $7 \mathrm{~d}$ at $37^{\circ} \mathrm{C}$ under $5 \% \mathrm{CO}_{2}$. Ten milligrams of CCK-8 were added to each well plate and incubated for an additional $4 \mathrm{~h}$. The supernatant was measured at $450 \mathrm{~nm}$ wavelength. Live and dead assay for observing alive and dead cells were investigated by confocal microscope (LSM800 w/Airyscan, Carl Zeiss, Oberkochen, Germany) for 1, 3, and 7 days of culture. At the determined time intervals, cell-cultured FDs were rinsed with PBS three times. A total of $2 \mu \mathrm{M}$ of Fluorescent marker Calcein AM and $4 \mu \mathrm{M}$ of ethidium homodimer (EthD-1) were used for staining alive and dead cells, respectively. Alive and dead cells were observed in a green color using an argon laser $(488 \mathrm{~nm})$ and in a red color using a HeNe laser (543 $\mathrm{nm})$. Bright field and fluorescence microscopic images were recorded by a CCD color digital camera (QImaging Retiga 4000R). 


\subsection{Characterization of 2-GHC-FD-1, 2-GHC-FD-4 and 2-GHC-FD-8}

\subsubsection{Tensile Strength Measurement}

Tensile tests were performed at room temperature by using a universal testing machine (UTM 4476, Instron, Norwood, MA, USA) according to ASTM D3574. A specific size of 2-GHC-FD-1 (width: $1 \mathrm{~cm}$ and length $3 \mathrm{~cm}$ ), 2-GHC-FD-4 (width: $1 \mathrm{~cm}$ and length $3.3 \mathrm{~cm}$ ) and 2-GHC-FD-8 (width: $1 \mathrm{~cm}$ and length $3.2 \mathrm{~cm}$ ) were prepared. The test conditions were a speed of $10 \mathrm{~mm} / \mathrm{min}$ and a chart speed of $20 \mathrm{~mm} / \mathrm{min}$, using 5-kgf load cells.

\subsubsection{WVTR Test}

The WVTR test was performed according to EN 13726-2 “Test methods for primary wound dressing. Part 2: Moisture vapor transmission rate of permeable film dressings After fixing the bottom of the moisture-permeable cup with a flat plate, $20 \mathrm{~mL}$ of distilled water was added. The initial weights ( $\left.w_{1}\right)$ of 2-GHC-FD-1, 2-GHC-FD-4, and 2-GHC-FD-8 were measured, fixed on a cup, and the cups were placed in a thermo-hygrostat. FDs were maintained at $37^{\circ} \mathrm{C}$ and below $20 \%$ humidity. After $24 \mathrm{~h}$, the weights $\left(w_{2}\right)$ of FDs were measured, and the WVTR was determined using the following formula:

$$
W V T R=\frac{w_{1}-w_{2}}{m^{2} \cdot 24 \mathrm{hr}} \times 10^{3} \mathrm{~g}
$$

where $w_{1}, w_{2}$, and $m^{2}$ indicate the initial weight of FDs, the weight of FDs after the test, and the area of the FDs, respectively.

\subsubsection{Absorption Rate Test}

The absorption rate test was performed according to EN 13726-1 "Test methods for primary wound dressings. Part 1: Aspects of absorbency. Three types of FDs, 2-GHC-FD-1, 2-GHC-FD-4, and 2-GHC-FD-8 were cut to a size of $2 \mathrm{~cm} \times 2 \mathrm{~cm}$ and weighed $\left(w_{1}\right)$. After placing the regular size of FDs in Petri dishes, distilled water of 40-fold greater weight than the initial weight of FDs, heated at $37^{\circ} \mathrm{C}$ was added and heated for an additional $30 \mathrm{~min}$. The soaked FDs were weighed after eliminating water on the surface of the FDs, and the absorption rate was calculated using the following formula:

$$
\text { Absorption rate }=\frac{w_{1}-w_{2}}{m^{2}}\left(\mathrm{~g} / \mathrm{cm}^{2}\right)
$$

where $w_{1}, w_{2}$, and $m^{2}$ indicate the initial weight of FDs, the weight of FDs after the test, and the initial area of the FDs, respectively. Retention capacity was calculated according to following formula:

$$
\text { Retention capacity }=\frac{\mathrm{D}-\mathrm{A}}{\mathrm{A}}\left(\mathrm{g} / \mathrm{cm}^{2}\right)
$$

where $\mathrm{D}, \mathrm{A}$ indicate initial weight and retention weight of $\mathrm{FD}$, respectively.

\subsubsection{Animal Intradermal Reactivity Test}

For intradermal reactivity tests of FDs (2-GHC-FD-1, 2-GHC-FD-4 and 2-GHC-FD8), two types of solvents, sterilized physiological saline as a polar solvent and vegetable soybean oil as a nonpolar solvent, were used for the elution of the FDs, which was evaluated using Table 2. In the case of the soybean oil, it was filtered using a $0.2 \mu \mathrm{m}$ syringe filter for sterilization. The two solvents were used as the controls. First, a specific weight of FDs ( $0.5 \mathrm{~g} /$ each FD, solvent: $10 \mathrm{~mL})$ was sterilized using ethylene oxide followed by elution at $37^{\circ} \mathrm{C}$ for $72 \mathrm{~h}$. The hair on the back of the experimental rats ( $n=6$ for each FD) were removed using a razor and depilatory cream and cleaned with an alcohol swab. A specific volume $(1 \mathrm{~mL})$ of the control and experimental elution were intradermally injected. Polar solvent-derived and nonpolar-derived eluents were intradermally injected into the left and right back parts, respectively. After intradermal injection, the eluent-treated parts were carefully monitored for erythema, crusting, and edema. 
Table 2. Intradermal reactivity score evaluated by the degree of formation of erythema and callus, and edema.

\begin{tabular}{|c|c|}
\hline \multicolumn{2}{|c|}{ Formation of erythema and callus } \\
\hline No erythema & 0 \\
\hline Slight erythema & 1 \\
\hline Well-defined erythema & 2 \\
\hline Intermediate erythema & 3 \\
\hline Severe erythema (dark red) and callus & 4 \\
\hline \multicolumn{2}{|c|}{ Formation of edema } \\
\hline No edema & 0 \\
\hline Slight edema & 1 \\
\hline Well-defined edema & 2 \\
\hline Intermediate edema (about $1 \mathrm{~mm}$ ) & 3 \\
\hline Severe edema $(>1 \mathrm{~mm})$ & 4 \\
\hline Stimulus score at maximum & 8 \\
\hline
\end{tabular}

\subsection{Preparation of FDs Containing Various Concentrations of FGF-7}

As presented in Table 3, various concentrations of FGF-7 solutions were soaked in sterilized FDs $(1 \mathrm{~cm} \times 1 \mathrm{~cm})$ made of $2 \%(w / v)$ gelatin, $10 \%(w / w)$ HA (concentration calculated from the weight of gelatin), and $50 \%(w / w)$ CMCS (concentration calculated from the weight of gelatin), which was designated as 2-GHC-FD-8/F1 6. After lyophilization, FDs were used without further modification. All FDs were observed using an SEM (Bio-LV SEM, S-2250N, Hitachi, Japan). Freeze-dried FDs were placed on the mount using carbon tape. Before SEM observation, all FDs were coated with $\mathrm{Ag} / \mathrm{Pd}$ by using a plasma sputter (Emscope SC500K, London, UK). The FDs were observed at 200×.

Table 3. Sample lists of wound dressing FDs, containing various concentrations of FGF-7, ranging from 2 to $16 \times 10^{-11} \mathrm{M}$. the FD was prepared by mixing $2 w / v \%$ of gelatin, $5 w / w \%$ of $\mathrm{HA}$, and $10 w / w \%$ of CMCS.

\begin{tabular}{ccccc}
\hline Samples & $\begin{array}{c}\text { Gelatin } \\
(\boldsymbol{w} / \boldsymbol{v} \%)\end{array}$ & $\begin{array}{c}\text { HA } \\
(\boldsymbol{w} / \mathbf{w} \%)\end{array}$ & $\begin{array}{c}\text { CMCS } \\
(\boldsymbol{w} / \mathbf{w} \%)\end{array}$ & $\begin{array}{c}\text { FGF-7 } \\
\left(\times \mathbf{1 0}^{-\mathbf{1 1}} \mathbf{M}\right)\end{array}$ \\
\hline 2-GHC-FD-8/F1 & & & & 2 \\
2-GHC-FD-8/F2 & & & & 4 \\
2-GHC-FD-8/F3 & 2 & 5 & 10 & 8 \\
2-GHC-FD-8/F4 & & & & 16 \\
2-GHC-FD-8/F5 & & & & 32 \\
2-GHC-FD-8/F6 & & & & 64 \\
\hline
\end{tabular}

\subsection{Fourier Transform Infrared Spectroscopy (FTIR)}

The FDs, shown in Table 3, were recorded on a Spectrum GX FT-IR spectrometer (PerkinElmer, Boston, MA, USA). FTIR spectra was monitored from 400 to $4000 \mathrm{~cm}^{-1}$ with 256 scans and a resolution of $2 \mathrm{~cm}^{-1}$.

\subsection{Release Test of FGF-7}

FGF-7-loaded 2-GHC-FD-8/F1-6 were placed in Petri dishes $(90 \mathrm{~mm} \times 15 \mathrm{~mm})$, and PBS (pH 7.4) was added. The FDs were incubated at $37^{\circ} \mathrm{C}$ to determine the release periods. At each time interval (10, 20, $30 \mathrm{~min}$, and 1, 2, 4, 8, 12, 24, 36, $48 \mathrm{~h}), 1 \mathrm{~mL}$ of eluate from each sample was extracted, and the same volume of fresh PBS was added. All eluates were evaluated using the Human KGF/FGF-7 Quantikine ${ }^{\circledR}$ ELISA Kit (R\&D Systems, Minneapolis, MN, USA) according to the manufacturer's protocol. Briefly, all eluates were diluted 10,000-fold by using the RD5R buffer of the kit. The diluted eluates were transferred to a 96-well plate and incubated at room temperature for $3 \mathrm{~h}$. The eluates were measured at $450 \mathrm{~nm}$ by using a microplate reader, according to the manufacturer's protocol. 


\subsection{In Vivo Animal Study}

Forty-eight Balb/C mice $(20 \pm 3.2 \mathrm{~g}, 6$ weeks, mice per each group = 6; G-bio, Gwangju, Republic of Korea) were used to investigate skin wound healing [21,22]. Prior to this experiment, mice carried in animal laboratory was stabilized for 7 days in a breeding facility set at $22 \pm 3{ }^{\circ} \mathrm{C}$ and a humidity ranging from 30 to $70 \%$. After anesthetizing using ketamine hydrochloride (Ketara ${ }^{\circledR} ; 50 \mathrm{mg} / \mathrm{kg}$, YUHAN, Seoul, Republic of Korea) and Xyalizine hydrochloride (Rompun ${ }^{\circledR} ; 5 \mathrm{mg} / \mathrm{kg}$, Bayer Healthcare, Seoul, Republic of Korea), the back of each mouse was shaved, and the specific size of the wound (diameter: $1 \mathrm{~cm}$ ) was produced using a biopsy punch. The wounds were entirely covered with 2-GHC-FD-8 and 2-GHC-FD-8/F1-6, and protected with Tegaderm ${ }^{\mathrm{TM}}$ (St. Paul, MN, USA) and Coban ${ }^{\mathrm{TM}}$ (St. Paul, MN, USA) to minimize infection. During the experiment, mice was randomly divided in eight groups, including sham (control): group I (sham), group II (2-GHC-FD-8), group III (2-GHC-FD-8/F1), group IV (2-GHC-FD-8/F2), group V (2-GHC-FD-8/F3), group VI (2-GHC-FD-8/F4), group VII (2-GHC-FD-8/F5), and group VIII (2-GHC-FD-8/F6). At each time interval (days 7, 14, and 21), the wound size of each mouse was measured using the ImageJ program (National Institutes of Health, Bethesda, MD, USA). After 21 days, mice were sacrificed for histological evaluations.

\subsection{Hematoxylin and Eosin (HEE) and Masson's Trichrome (MT) Staining}

At twenty-one days after surgery, the mice used for the test were euthanized using $100 \% \mathrm{CO}_{2}$, and their skin tissues, including 2-GHC-FD-8 and 2-GHC-FD-8/F1-6-treated wounds, were removed. The tissues were fixed in $10 \%$ neutral-buffered formalin for $24 \mathrm{~h}$. For removing residual formalin, the tissue samples were washed with $0.1 \mathrm{M}$ PBS (pH 7.4) for $20 \mathrm{~min}$. Dehydration was conducted in a series of ethanol solutions from 70 to $100 \%$. The dehydrated tissues were embedded in paraffin and sectioned at $4 \mu \mathrm{m}$. For evaluating histopathological changes and collagen formation, the slides were stained with H\&E (ab ab245880, Abcam, Cambridge, UK) and MT (TRM-2, ScyTek, West Logan, UT, USA) according to manufacturer's guidelines, respectively [23]. There were twenty-four wounds per mouse per condition because twelve mice per each group with four wounds on its back per each mouse were used. Each groups included a total of three stained slides for $\mathrm{H} \% \mathrm{E}$ and $\mathrm{MT}$, and the histological evaluations were blindly performed. Three fields per each slide were observed.

The stained slides were visualized using a fluorescence microscope (AX70, TR-62A02, Olympus, Tokyo, Japan) at $2.0 \times(500 \mu \mathrm{m})$. The results were read by three histopathologists.

\subsection{Statistical Analysis}

All quantitative data were statistically analyzed using one-way analysis of variance (ANOVA) of Origin program (OriginLab ${ }^{\circledR}$, Northampton, MA, USA) followed by a posthoc test because all data were normally distributed. The normality test of distribution was assessed using the Shapiro-Wilk test provided by the SPSS software ISPSS Inc., Chicago, IL, USA). Quantitative data were analyzed five times and expressed as the mean \pm standard deviation $\left({ }^{*} p<0.05\right)$. The number of each sample for the animal test was determined using MedCalc Statistical Software (MedCalc Software bvba, Ostend, Belgium), using $\alpha(p=0.05)$ and power $(1 \beta=0.8)$.

\section{Results and Discussion}

3.1. Preparation and Characterization of Gelatin, CMCS, and HA-blended Foam Dressings (GHC-FDs)

\subsubsection{Preparation of FDs}

Table 1 shows the blending ratios of gelatin, $\mathrm{HA}$, and CMCS for the preparation of FDs. This blend was chemically crosslinked among natural hydrogels through an amide bond $[15,16]$. The carboxyl and amine groups of gelatin, the carboxyl group of HA, and the amine group of CMCS are related to amide bond formation through condensation reactions among the functional groups [24,25]. Hydrogelation was not observed in the nine samples 
prepared from $1 \%(w / v)$ gelatin; it was observed in 27 samples containing 2, 5, and 10\% $(w / v)$ gelatin. In our study, gelatin concentration significantly influenced hydrogelation. Therefore, the absence of hydrogelation at $1 \%(w / v)$ gelatin may be attributable to the relatively low concentration of gelatin related to amide bond formation. The FD samples designated as 2-GHC-FD-1-9, 5-GHC-FD-1-9, and 10-GHC-FD-1-9 for further experiments.

\subsubsection{Observation of Surface Morphology}

After lyophilization, the surface morphologies of the freeze-dried FDs, were observed using SEM (Figure 2). The porous structure of biomaterials for wound healing is a vital factor because it offers cell infiltration, high permeability, and diffusion of oxygen and nutrients [26]. Porous structures were observed in all samples, regardless of the concentrations of gelatin, HA, and CMCS, due to the lyophilization of the occupied water molecules.

\subsubsection{NIH/3T3 Cell Proliferation}

The cell proliferation results analyzed by the CCK-8 assay are shown in Figure 3. Gelatin is produced by heating collagen composed of Arg-Gly-Asp (RGD), resulting in the formation of a random-coiled domain. Therefore, it allows for the adhesion, spreading, and proliferation of cells $[27,28]$. CMCSs have been extensively investigated as wound dressings as they can improve cell adhesion and proliferation, and possess excellent biological functions, including antibacterial and biomimetic properties [10,29]. HA is a naturally occurring glycosaminoglycan (GAG) and a main component of the extracellular matrix (ECM). These characteristics quickly induce cell adhesion [30]. Compared with control, GHC-based samples remarkably exhibited significant difference in the cell proliferation. The FDs related to $2 \%, 5 \%$, and 10\% $(w / v)$ gelatin (2-GHC-FD-1-9, 5-GHC-FD-1-9, and 10-GHC-FD-1-9) had relatively lower cell proliferation than those in the control (well plate). This finding may be attributed to the difference in cellular behavior between twoand three-dimensional networks. Throughout the culture periods, compared with control (well-plate), the FDs had a significant difference in cell proliferation. The proliferation of all FDs gradually increased over $5 \mathrm{~d}$, but cell proliferation after $5 \mathrm{~d}$ was complicated. In 2-GHC-FD-1-9, FDs gradually improved cell proliferation throughout the culture period. However, in 5-GHC-FD-1-9 and 10-GHC-FD-1-9, FDs (5-GHC-FD-5, 6, 8, 9 and 10-GHCFD-5, 6, 8, 9) with a relatively large amount of HA and CMCS exhibited decreased cell proliferation. These results can be ascribed to the effects of the mechanical properties of FDs.

\subsection{Characterizations of 2-GHC-FD-1, 2-GHC-FD-4, and 2-GHC-FD-8}

The three types of FDs were selected based on the results of the afore-mentioned cell proliferation test. Evaluating mechanical properties, such as tensile strength, is a significant factor in preparing biomaterial scaffolds in various tissue-engineering fields. Ideal biomaterial scaffolds in tissue engineering have mechanical properties similar to those of native tissue or organs intended for regeneration. For example, native skin has a tensile strength between 5 and $30 \mathrm{MPa}$ and an elongation between 35 and 115\% [31,32]. This may indicate that cells related to skin generation actively proliferate in biomaterial scaffolds adjusted to the tensile strength and elongation of native tissue. In Figure $4 \mathrm{a}$, various tensile strengths and elongations were confirmed according to the concentration variables of gelatin, HA, and CMCS. Specifically, 2-GHC-FD-1, 2-GHC-FD-4, and 2-GHCFD-8 exhibited tensile strengths below $5 \mathrm{MPa}$. Furthermore, 2-GHC-FD-1 and 2-GHC-FD-4 exhibited shorter elongation (19\% and 54\%) than 2-GHC-FD-8 (78\%). The results of 2-GHCFD-8 had a significant difference as compared to those of 2-GHC-FD-1 and 2-GHC-FD-4. These results may imply that 2-GHC-FD-8 is a more appropriate scaffold than 2-GHC-FD-1 and 2-GHC-FD-4 for wound healing. 
(a)
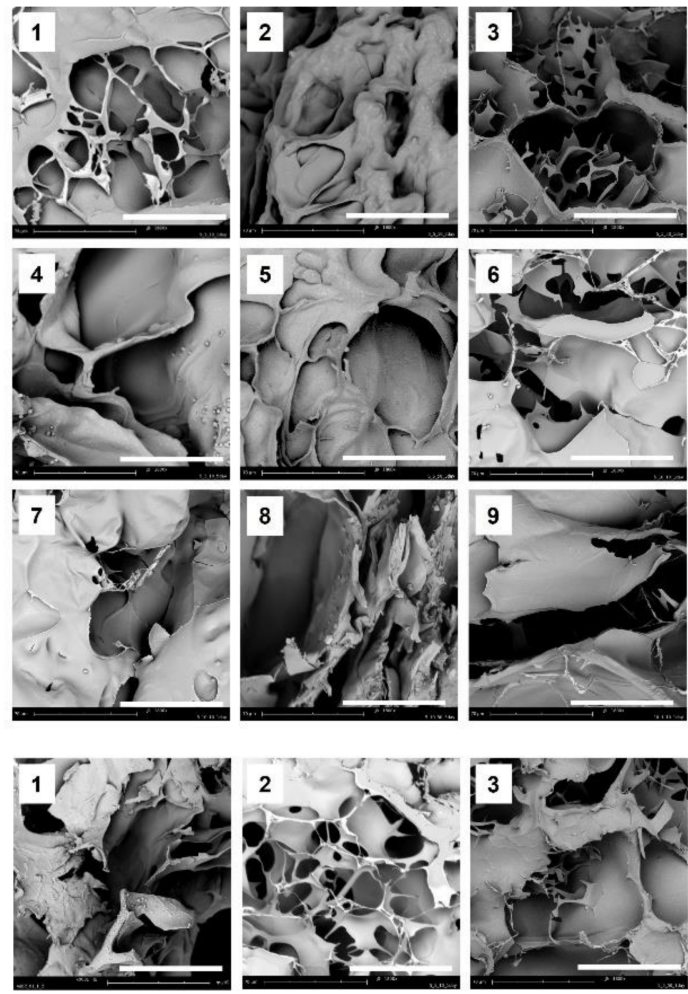

(b)
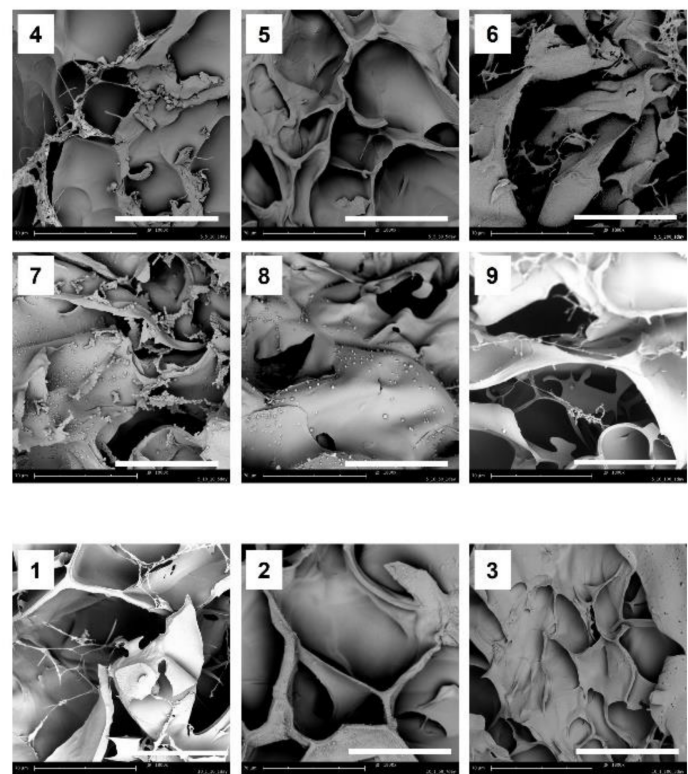

(c)
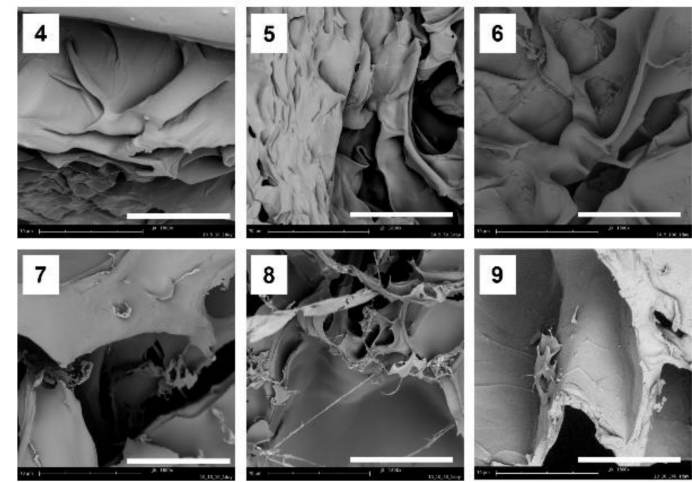

Figure 2. Surface morphologies of lyophilized 2-GHC-FD-1-9, 5-GHC-FD-1-9, and 10-GHC-FD-1-9 observed by FE-SEM at 1800×. (a) 2-GHC-FD-1-9, (b) 5-GHC-FD-1-9, and (c) 10-GHC-FD-1-9. White scale bars indicate $70 \mu \mathrm{m}$. 

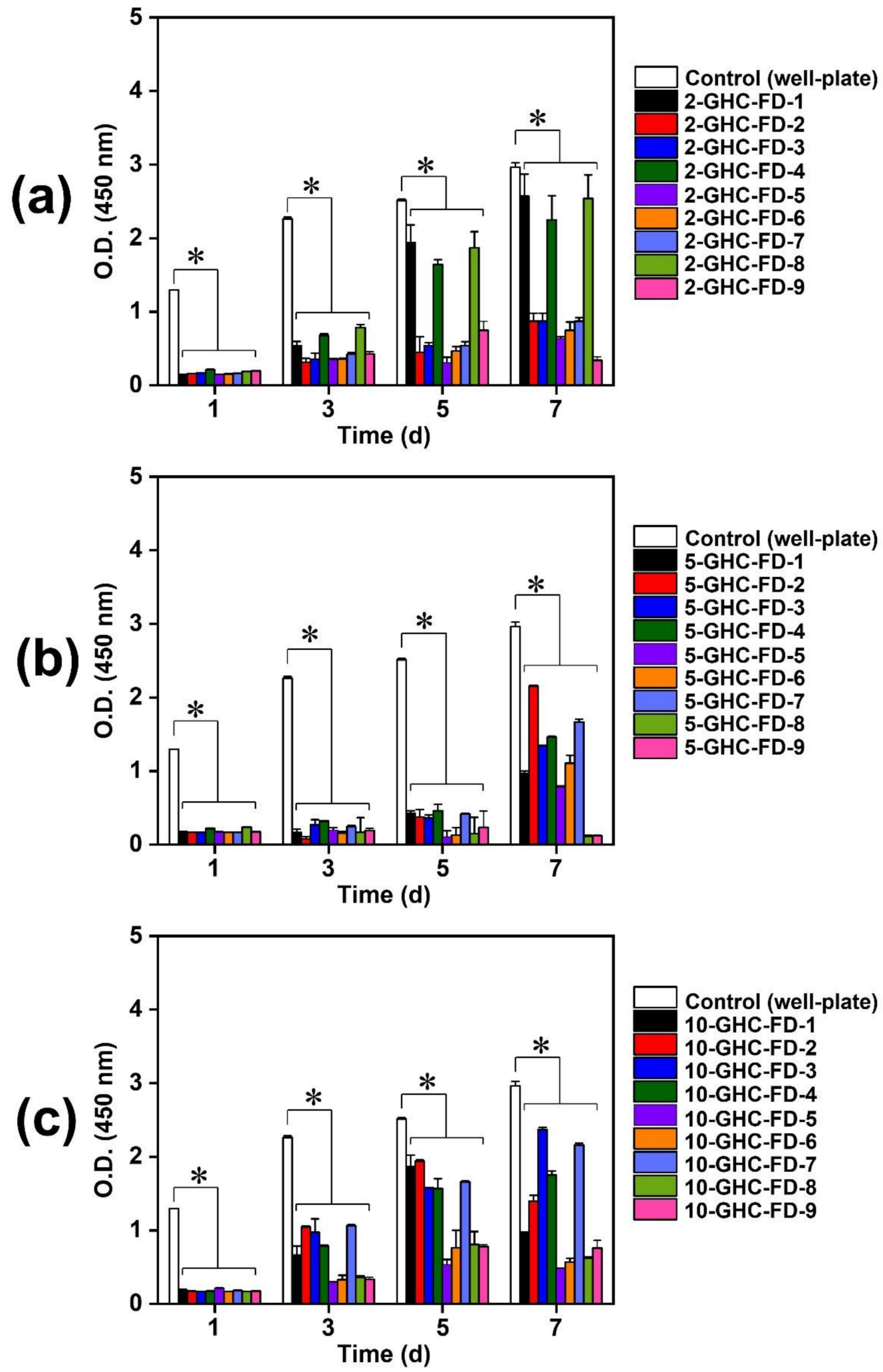

Figure 3. O.D. values of (a) 2-GHC-FD-1-9, (b) 5-GHC-FD-1-9, and (c) 10-GHC-FD-1-9 measured by CCK-8 assay at $450 \mathrm{~nm}$. The test was performed for $1,3,5$, and 7 days $(n=5)$. As a control, O.D. of cells cultured on well-plate was used. The statistical significance was indicated by an asterisk $\left(^{*}\right)$ for $p<0.05$. The FD samples were compared to control (well-plate). At $(\mathbf{a}-\mathbf{c})$ graphs, the FD samples had significant differences as compared to control (well plate). The type of this result is involved in continuous data. 
Tensile strength test

UTM

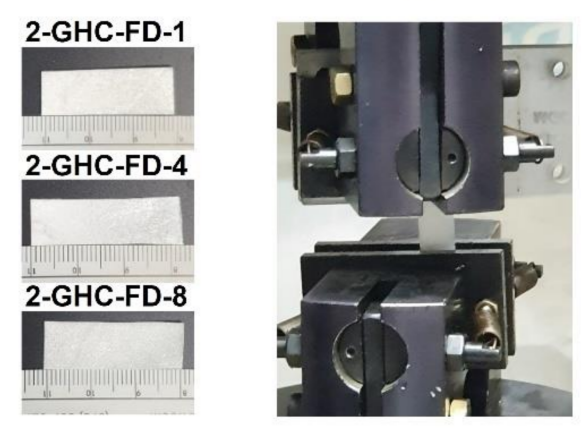

WVTR test

Before

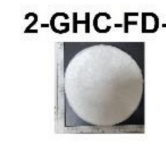

2-GHC-FD-4

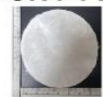

2-GHC-FD-8

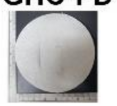

After (a)

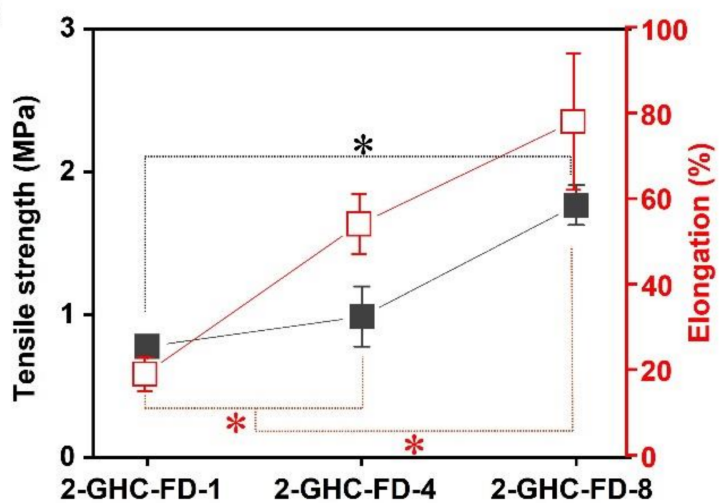

(b)
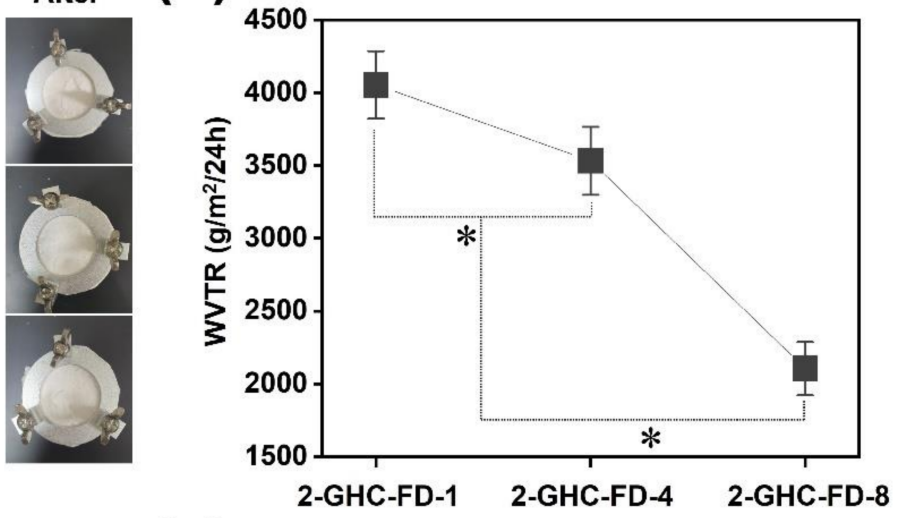

Absorption rate test

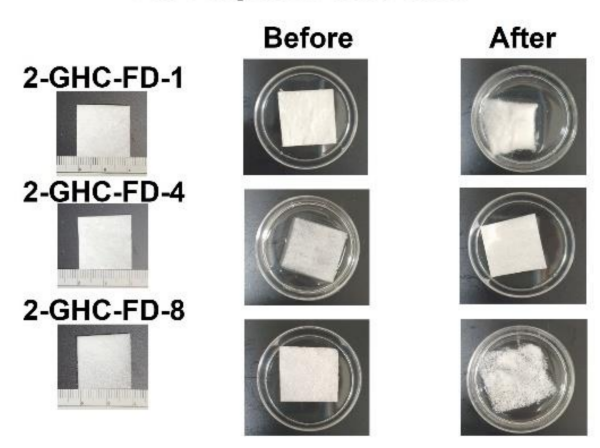

(c)

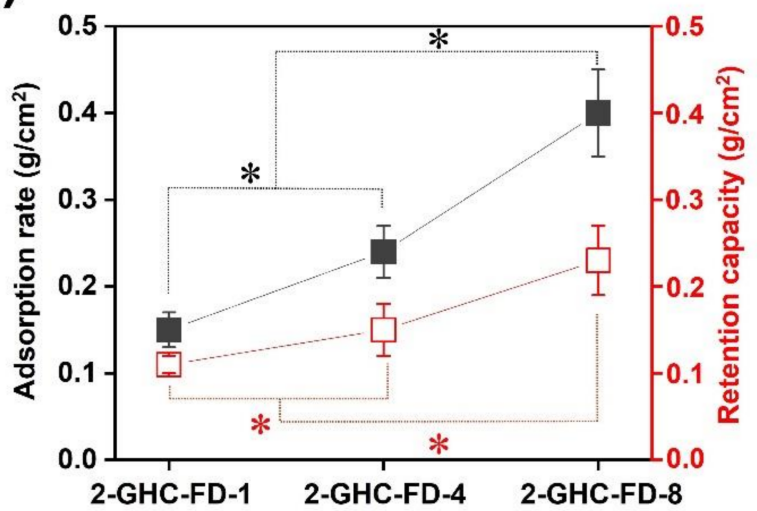

Figure 4. (a) Tensile strengths and elongations, (b)WVTR, and (c) absorption rate and retention capacity of 2-GHC-FD-1, GHC-FD-4, and GHC-FD-8. The test was performed five times. The statistical significance was indicated by an asterisk $\left(^{*}\right)$ for $p<0.05$. The results of FD samples compared each other. In the tensile strength of (a) graph, 2-GHC-FD-8 had significant differences as compared to 2-GHC-FD-1. The elongation result of 2-GHC-FD-8 had significant differences as compared to those of 2-GHC-FD-1 and 2-GHC-FD-4. In WVTR results of (b) graph, 2-GHC-FD-8 had significant differences as compared to 2-GHC-FD-1 and GHC-FD-4. In (c) graph, the adsorption rate and retention capacity of 20GHC-FD-8 had significant differences as compared to those of 2-GHC-FD-1 and 2-GHC-FD-4. The type of this result is involved in continuous data.

An optimal moisture environment is essential for wound healing acceleration without causing substantial side effects $[33,34]$. This wetted condition leads to the acceleration of re-epithelialization, reduction of inflammation, necrosis, and scar formation [1]. Furthermore, wound fluid in a wetted condition stimulated the proliferation of keratinocytes and fibroblasts for wound repair [1]. Therefore, ideal wound dressings must provide adequate 
wetting conditions to prevent dehydration. Lee et al. explained that a three-dimensional wound dressing with approximately $2028.3 \mathrm{~g} / \mathrm{m}^{2} / 24 \mathrm{~h}$ provides an optimal moisture environment for improving the proliferation and function of fibroblasts and epidermal cells [35]. The WVTR results of the FD samples are shown in Figure 4b. 2-GHC-FD-1 and 2-GHC-FD-4 had the WVTR of 4054.4 and $3532.2 \mathrm{~g} / \mathrm{m}^{2} / 24 \mathrm{~h}$, respectively, on the other hand, 2-GHC-FD-8 exhibited $2105.3 \mathrm{~g} / \mathrm{m}^{2} /$ per $24 \mathrm{~h}$. The results of 2-GHC-FD-8 had a significant difference as compared to those of 2-GHC-FD-1 and 2-GHC-FD-4. This result indicates that 2-GHC-FD-8 could be an optimal scaffold for wound healing acceleration.

The absorption of exudate from the wound influences wound healing. If the absorption rate is low, the exudate remains in the wound, causing skin maceration and bacterial infection $[2,35]$. Therefore, balancing the absorption rate and retention capacity of the exudate in wound dressings must be appropriately controlled. As exudates are formed differently depending on the wound type and healing stage, wound dressing must be chosen by considering the rate of exudate formation to avoid drying-out or maceration of wounds [3]. The absorption rate/retention capacities of 2-GHC-FD-1, 2-GHC-FD-4, and 2-GHC-FD-8 are shown in Figure 4c. The results of 2-GHC-FD-8 had a significant difference as compared to those of 2-GHC-FD-1 and 2-GHC-FD-4. The absorption/retention capacities of 2-GHC-FD-8 were noticeably higher than those of 2-GHC-FD-1 and 2-GHCFD-4. Their absorption/retention capacities were $0.15 / 0.11 \mathrm{~g} / \mathrm{cm}^{2}, 0.24 / 0.15 \mathrm{~g} / \mathrm{cm}^{2}$, and $0.40 / 0.23 \mathrm{~g} / \mathrm{cm}^{2}$, respectively.

This test was conducted using ISO-10993-10 " "Biological evaluation of medical devices: Tests for irritation and skin sensitization." It is a biological stability evaluation of medical devices applied to the skin, eyes, and mucous membranes, and must be performed. Figure 5 and Table 4 shows the results of the intradermal reactivity test using FDs for 1, 24, 48, and $72 \mathrm{~h}$. As shown in Figure 4, no abnormal skin responses were observed in the FDs. For a further investigation of the intradermal responses, the degree of erythema, incrustation, and edema was determined in polar and nonpolar solvents. The findings demonstrated no abnormality in the solvents.

Table 4. Score of animal intradermal reactivity of 2-GHC-FD-1, 2-GHC-FD-4, and 2-GHC-FD-8 observed at 24,48 , and $72 \mathrm{~h}$ after injection using polar and non-polar solvents. The reactivity was confirmed by erythema, callus, and edema.

\begin{tabular}{|c|c|c|c|c|c|}
\hline & \multirow[b]{2}{*}{ Time } & \multicolumn{2}{|c|}{ Control } & \multicolumn{2}{|c|}{ 2-GHC-FD-1,4,8 } \\
\hline & & $\begin{array}{c}\text { Polar } \\
\text { Solvent }\end{array}$ & $\begin{array}{l}\text { Non-Polar } \\
\text { Solvent }\end{array}$ & $\begin{array}{c}\text { Polar } \\
\text { Solvent }\end{array}$ & $\begin{array}{c}\text { Non-Polar } \\
\text { Solvent }\end{array}$ \\
\hline \multirow{3}{*}{ Erythema/Callus } & 24 & 0 & 0 & 0 & 0 \\
\hline & 48 & 0 & 0 & 0 & 0 \\
\hline & 72 & 0 & 0 & 0 & 0 \\
\hline \multicolumn{2}{|c|}{ Total score } & 0 & 0 & 0 & 0 \\
\hline \multirow{3}{*}{ Edema } & 24 & 0 & 0 & 0 & 0 \\
\hline & 48 & 0 & 0 & 0 & 0 \\
\hline & 72 & 0 & 0 & 0 & 0 \\
\hline \multicolumn{2}{|c|}{ Total score } & 0 & 0 & 0 & 0 \\
\hline
\end{tabular}




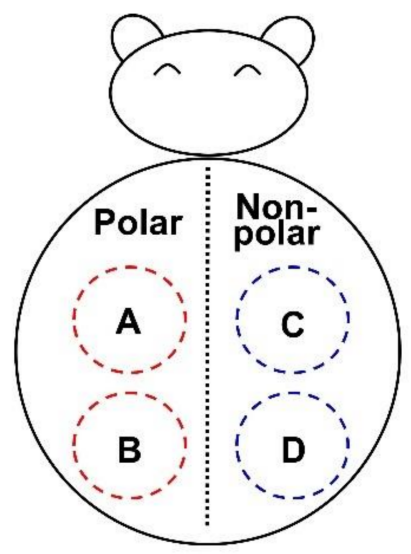

A: Sterilized physiological saline

B: Elution of 2-GHC-FD-1,4,8 in saline

C: Vegetable soy bean oil

D: elution of $2-$ GHC-FD-1,4,8 in soy bean oil

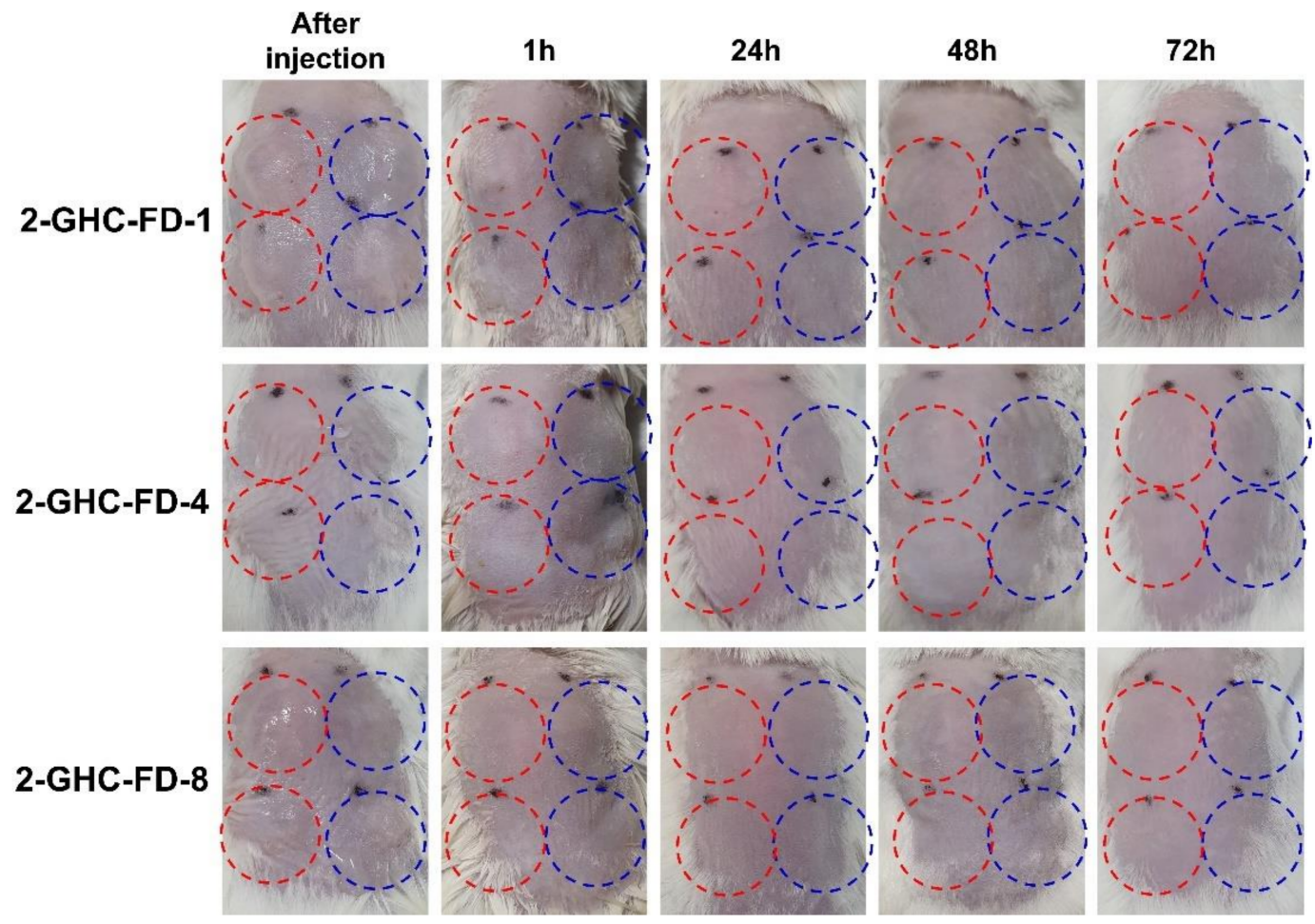

Figure 5. Macroscopic appearances of backs of mice injected with elution from 2-GHC-FD-1, 2-GHC-FD-4, and 2-GHCFD-8. This test was performed for 1, 24, 48, and $72 \mathrm{~h}$ after injection. Red dotted circles-(A) sterilized physiological saline; (B) elution of 2-GHC-FD-1,4,8 saline. Sky blue dotted circles-(C) vegetable soy bean oil; (D) elution of 2-GHC-FD-1,4,8 in soy bean oil. The black points indicate injection position.

\subsection{Characterization of FGF-7-Loaded 2-GHC-FD-8 (2-GHC-FD-8/F)}

As a platform for loading FGF-7, 2-GHC-FD-8 was selected based on the aforementioned cell proliferation, animal intradermal reactivity, WVTR, and absorption rate tests. The 2-GHC-FD-8 containing FGF-7 ranging from $2 \times 10^{-11} \mathrm{M}$ to $64 \times 10^{-11} \mathrm{M}$ designated as 2-GHC-FD-8/F1-6, as shown in Table 3.

\subsubsection{FTIR Spectra}

FTIR is a widely used analytical method for analyzing structural properties of materials and a pivotal technique for characterizing polymeric and biopolymeric materials [36]. Gelatin, CMCS, and HA commonly possess functional groups, including $\mathrm{OH}\left(3303 \mathrm{~cm}^{-1}\right)$, 
$\mathrm{CH}\left(2926 \mathrm{~cm}^{-1}, \mathrm{C}=\mathrm{O} /\right.$ amide I $\left(1620 \mathrm{~cm}^{-1}\right)$, and amide II $\left(1511 \mathrm{~cm}^{-1}\right)$. The three polymers also have functional groups related to amides I and II. Besides the common groups, $\mathrm{NH}_{2}$ groups exist in the backbone of gelatin. Loading of various concentrations of FGF-7 in 2-GHC-FD-8 was investigated by a FTIR analysis, as shown in Figure 6. 2-GHC-FD-8/F1 6 showed an increased intensity in the functional groups, as compared to 2-GHC-FD-8. This finding can be attributed to the loading of FGF-7.

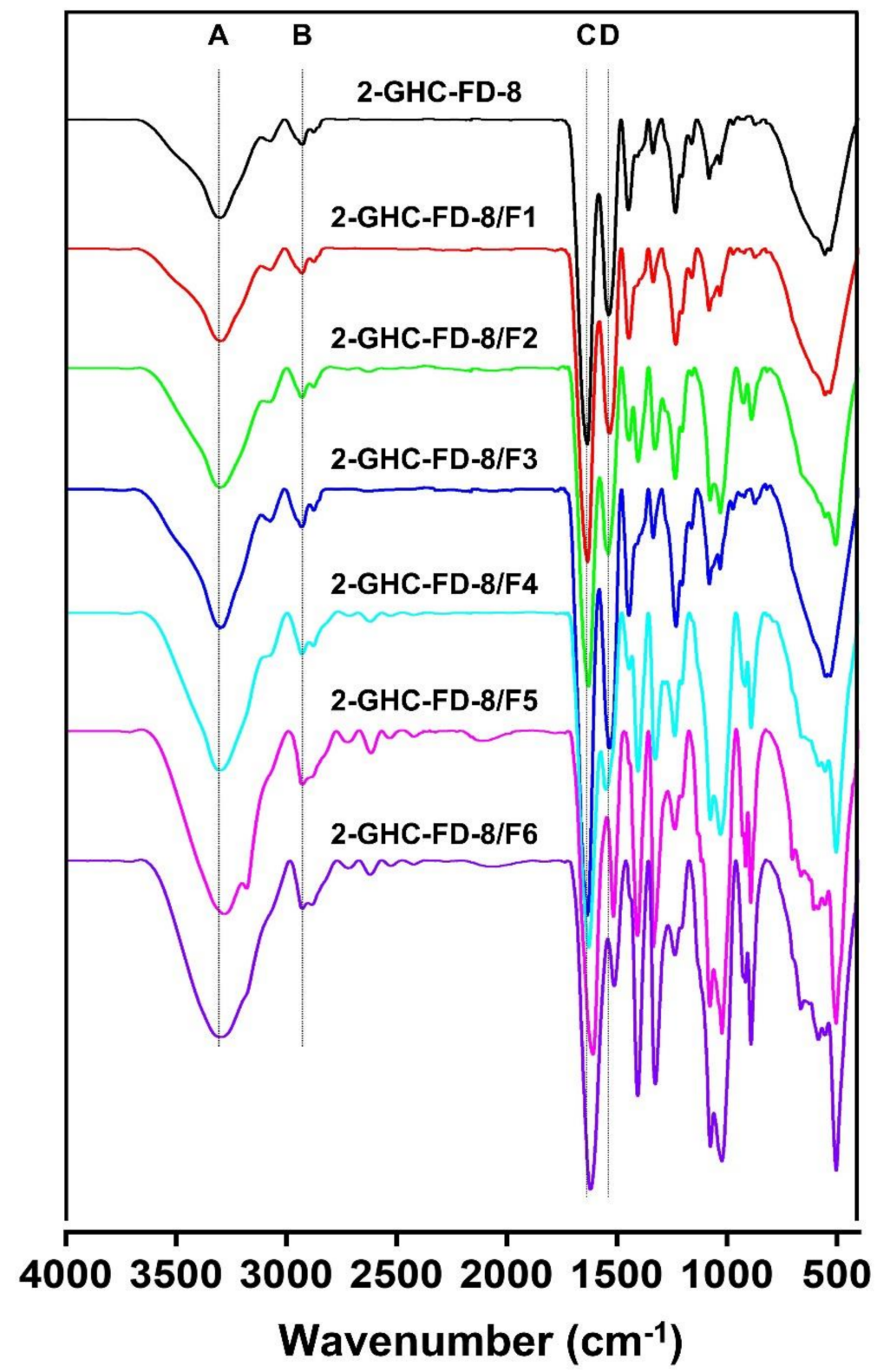

Figure 6. FTIR spectra of 2-GHC-FD-8/F1-6 monitored from 400 to $4000 \mathrm{~cm}^{-1}$. A, B, C, and D indicate $\mathrm{OH}, \mathrm{CH}, \mathrm{C}=\mathrm{O} /$ amide $\mathrm{I}$, and amide II signals, respectively.

\subsubsection{Observation of Surface Morphology and Porosity}

Surface morphologies of the freeze-dried GHC and 2-GHC-FD-8/F1-6 were observed using SEM (Figure 7). All FDs showed interconnected porous structures. This surface characteristic mimics naturally occurring tissue structures, promoting the exchange of gases and nutrients for cell proliferation [37]. To improve cell growth, adhered cells absorb nutrients and remove metabolites via pores. This pore size must be adequately controlled because cells cannot migrate into scaffolds with tiny pores and adhere to scaffolds with 
large pores [37]. All FDs showed similar pore sizes, indicating that cell proliferation was not affected by the pore size.
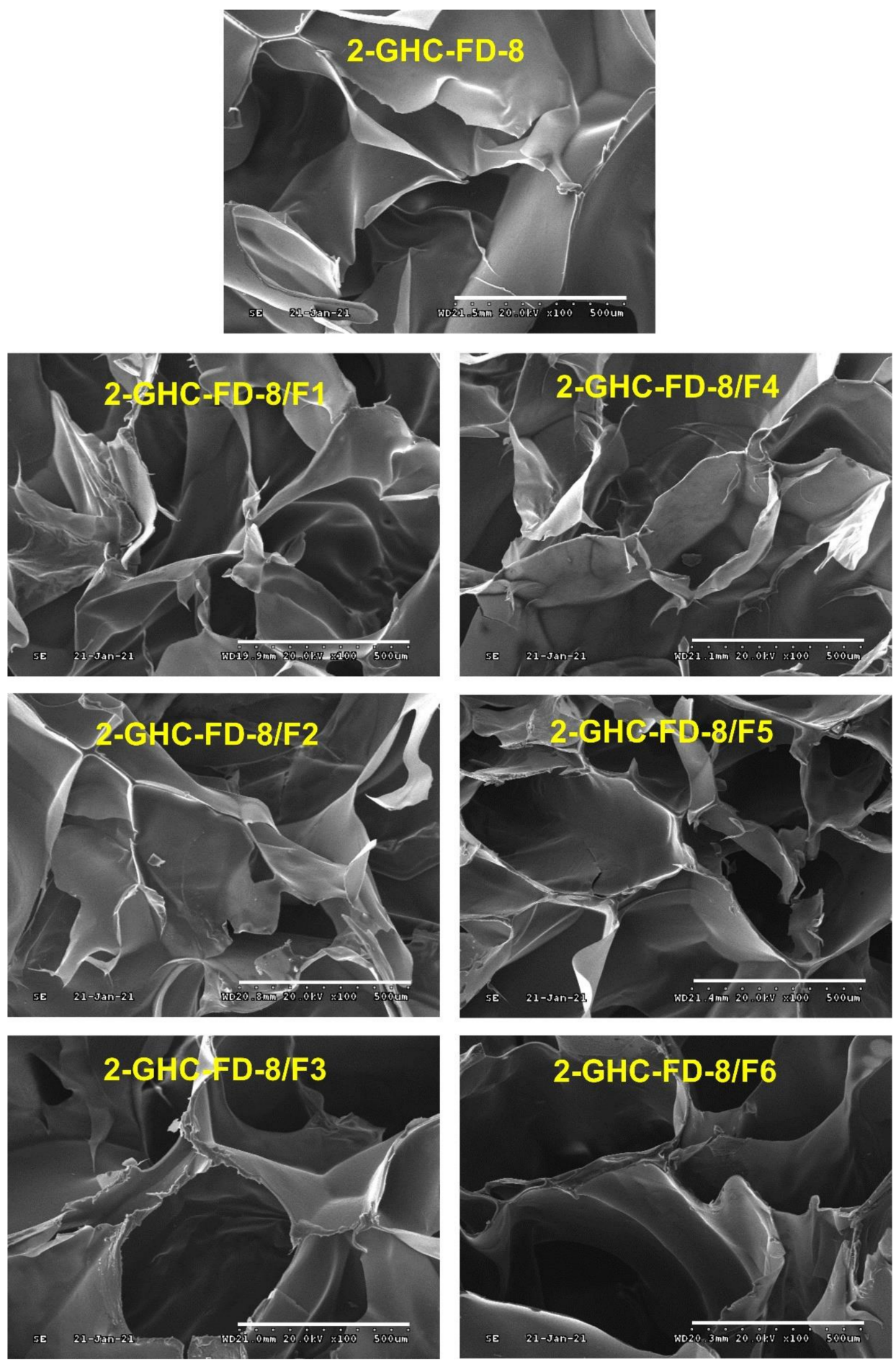

Figure 7. Surface morphologies of 2-GHC-FD-8/F1-6 observed by SEM at $100 \times$. White scale bars indicate $500 \mu \mathrm{m}$.

\subsubsection{Live and Dead Assay}

Figure 8 shows the cell proliferation of NIH3T3-E1 cells cultured on 2-GHC-FD-8 and 2-GHC-FD-8/F1 6, investigated by live/dead assay. Cell proliferation on 2-GHCFD-8 was used as a control. Throughout the culture period, alive cells were markedly present in 2-GHC-FD-8/F1-3. Above all, cells seemed to be actively proliferated in 2- 
GHC-FD-8/F3. Frederic et al. found that cells proliferate gradually until a specific FGF-7 concentration of $7.5 \times 10^{-11} \mathrm{M}$, and the proliferation sharply decreased thereafter [38]. Our results also showed a parabolic cell proliferation, in which cell proliferation increased until $8.0 \times 10^{-11} \mathrm{M}$ and decreased thereafter. In addition, 2-GHC-FD-8/F1 6 exhibited higher cell proliferation rate than 2-GHC-FD-8. The results showed that cell proliferation was affected by the FGF-7 concentration. In addition, it was proven that an adequate concentration of FGF-7 is a prerequisite for improving fibroblast proliferation, despite FGF-7 being related to fibroblast proliferation.

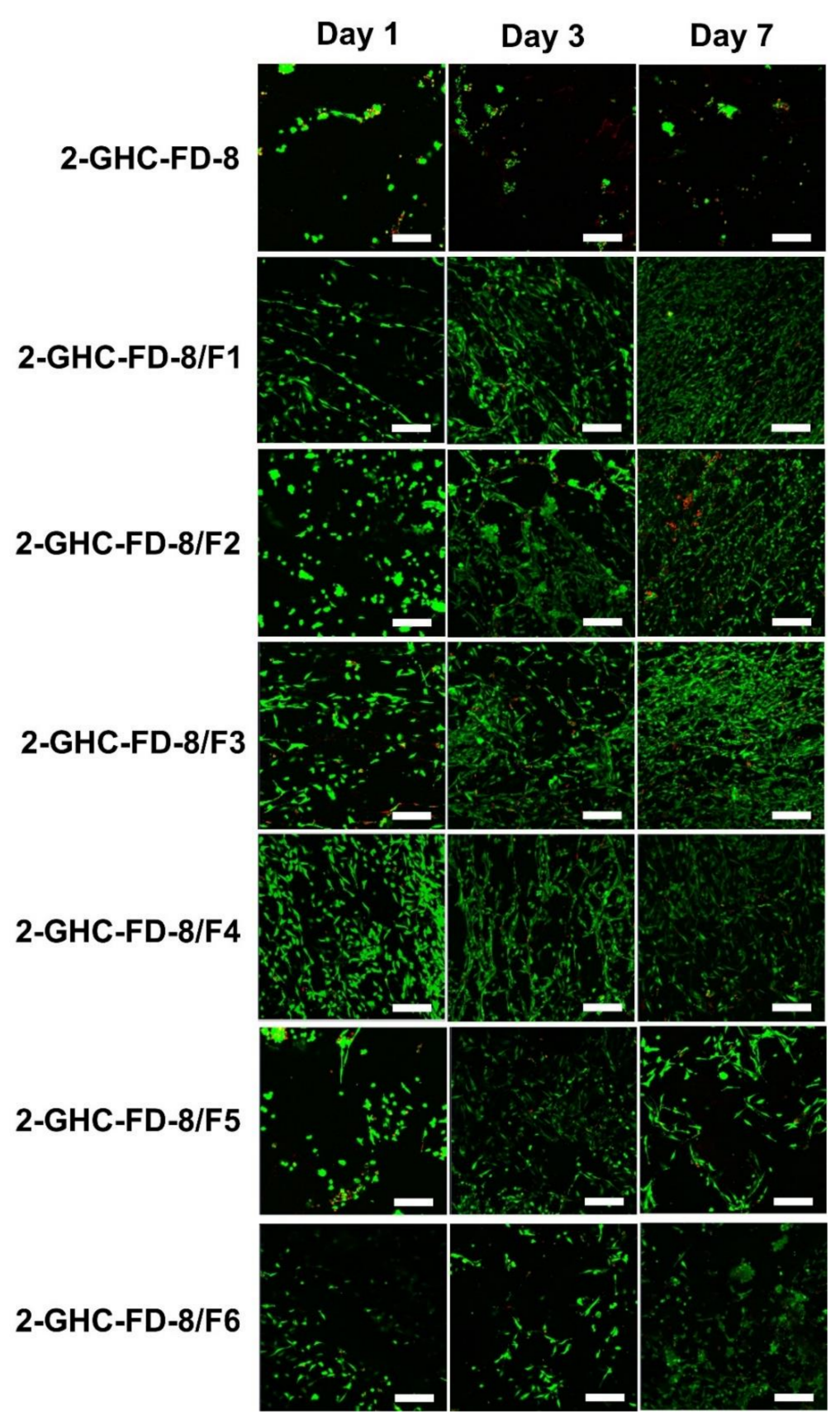

Figure 8. Confocal images of NIH/3T3 cells cultured on 2-GHC-FD-8 and 2-GHC-FD-8/F1-6 for 1, 3 , and 7 . The green and red colored cells indicate live and dead cells, respectively. White bars indicate $60 \mu \mathrm{m}$. Magnification is $10 \times$. 


\subsection{Release Behavior of FGF-7}

A controlled release of growth factors in a sustained manner can improve the proliferation and differentiation of cells, consequently accelerating wound healing [39]. Scaffolds of the porous structure provide a controlled release of growth factors, followed by applications of tissue engineering [40-42]. In Figure 9, porous 2-GHC-FD-8, in common with the afore-mentioned reports, displayed two release patterns: Initial burst and sustained release. In 2-GHC-FD-8/F1 6, FGF-7 was rapidly released within $1 \mathrm{~h}$ and released sustainably for $48 \mathrm{~h}$. The initial burst and controlled release were caused by FGF-7 on the surface and in the 2-GHC-FD-8 matrix.

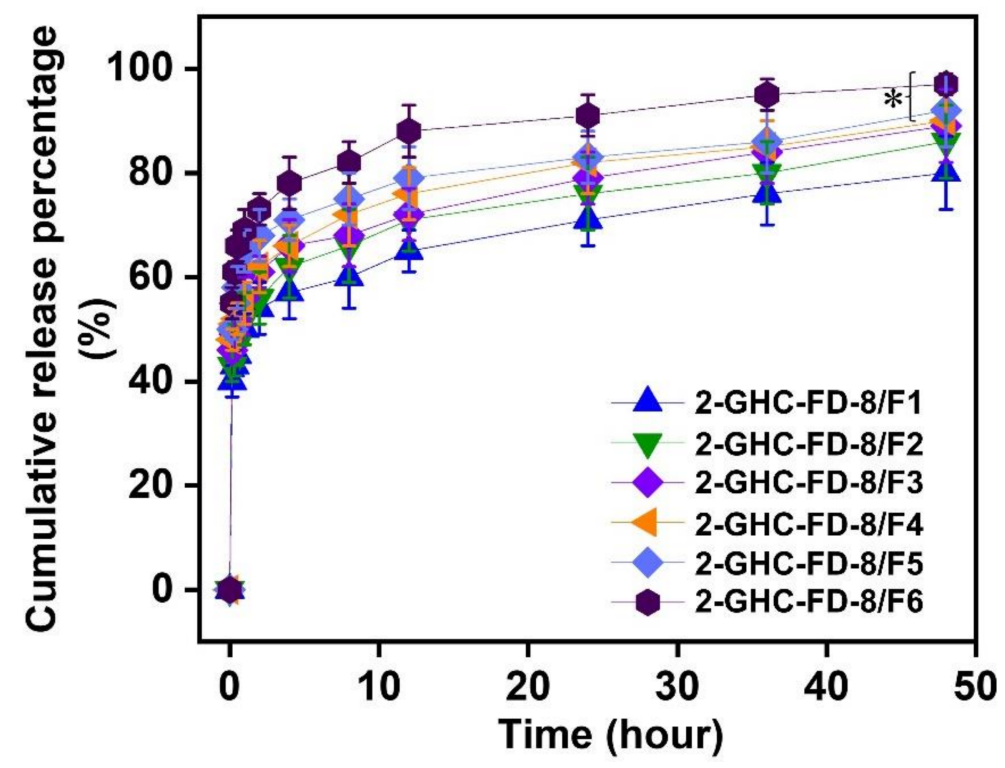

Figure 9. Cumulative release percentage of FGF-7 in 2-GHC-FD-8/F1-6 measured at $37^{\circ} \mathrm{C}$ for $48 \mathrm{~h}$. The test was performed five times. The statistical significance was indicated by an asterisk $\left({ }^{*}\right)$ for $p<0.05$. At 48 h, 2-GHC-FD-8/F5-6 has significant differences as compared to 2-GHC-FD-8/F1. This type of result is involved in continuous data.

\subsection{Macroscopic Observation and Size Calculation of Remaining Wounds}

An in vivo animal test for wound healing evaluation was conducted using skin excisional mice as animals can provide abundant, controllable, and accurate information for wound healing studies. In addition, $1 \mathrm{~cm}$ of wound size for our animal test was determined because the size of $0.5 \mathrm{~cm}$ is automatically recovered within $15 \mathrm{~d}[43,44]$. The wounds treated with 2-GHC-FD-8 and 2-GHC-FD-8/F1-6 were macroscopically observed for 7, 14 , and $21 \mathrm{~d}$ after surgery, and the remaining wound area was investigated (Figure 10). Although the wounds were produced using biopsy punches with a diameter of $1 \mathrm{~cm}$, practical wound sizes showed a small difference because they were produced manually. The macroscopic appearances of wounds treated with 2-GHC-FD-8 and 2-GHC-FD-8/F1 6 was shown in Figure 10a. The 2-GHC-FD-8 treatment accelerated wound recovery more rapidly than the control. Compared to 2-GHC-FD-8, the addition of FGF-7 to 2-GHC-FD-8 accelerated wound closure, in which the defect size remarkably decreased until FGF-7 increased to $8.0 \times 10^{-11} \mathrm{M}$ and was maintained thereafter. These findings indicate that 2-GHC-FD-8 and FGF-7 are important factors for accelerating wound healing. Figure 10b shows the remaining wound area calculated by the Image J program on days $0,7,14$, and 21 after wound production. Approximately $80 \%$ wound closure was observed in the control group after $21 \mathrm{~d}$, and $90 \%$ was observed in the 2-GHC-FD-8 group. Notably, 2-GHC-FD-8/F1-3 resulted in more remarkable wound closure than 2-GHC-FD-8/F4-6 for $21 \mathrm{~d}$. In special, 2-GHC-FD-8/F3 decreased wound closure markedly, indicating that $8.0 \times 10^{-11} \mathrm{M}$ of FGF-7 is a threshold concentration for wound healing acceleration. The remaining wound area of control, 2-GHC-FD-8, and 2-GHC-FD-8/F1 6 decreased from 
$100 \%$ to $32 \pm 5 \%$, to $17 \pm 4 \%, 11 \pm 3 \%, 12 \pm 4 \%, 9 \pm 2 \%, 13 \pm 4 \%, 14 \pm 5 \%$, and $15 \pm 3 \%$, respectively.

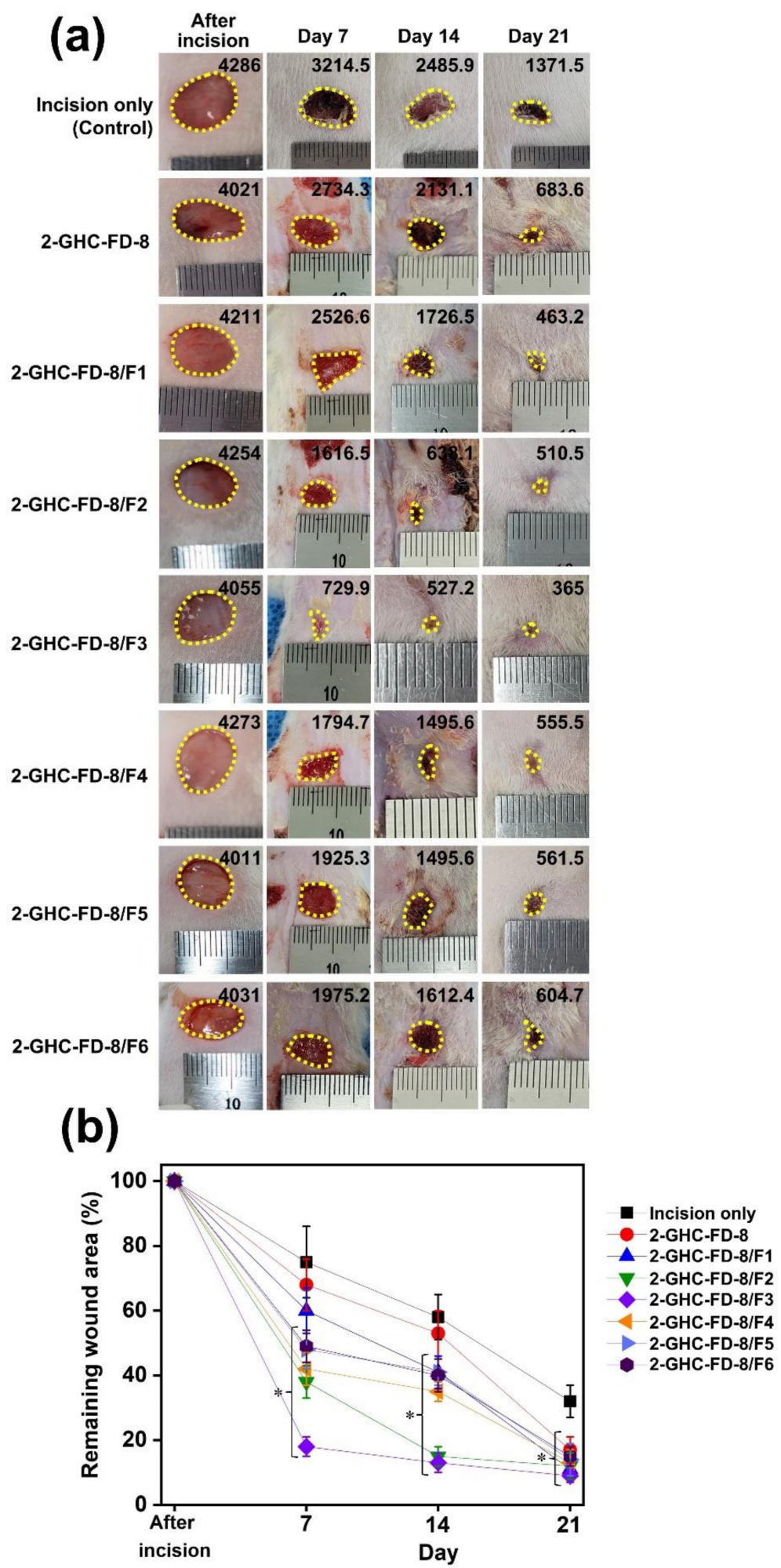

Figure 10. (a) Macroscopic appearances; and (b) remaining area of wounds treated with 2-GHC-FD-8 and 2-GHC-FD-8/F1-6 for 7, 14, and 21 days. In each photo, the black-colored number of upper-right indicates were calculated by an Image J program, indicating the area of remaining wounds. In (b) graph, the statistical significance was indicated by an asterisk $\left(^{*}\right)$ for $p<0.05$. The results of the FD samples were compared to that of incision only. The type of this result is involved in continuous data. 


\subsection{Histological Evaluation}

Histopathological changes in the control and all hydrogel-treated wounds for 7, 14, and $21 \mathrm{~d}$ were investigated using H\&E and MT staining (Figure 12). Angiogenesis is an important factor for wound healing [45]. This new angiogenesis is usually involved in the proliferative phase of wound healing process, which is produced by the action of endothelial cells and various cytokines such as FGF and vascular endothelial growth factor (VEGF) [46].

On day 7, 2-GHC-FD-8-based samples showed more noticeable angiogenesis than control. In addition, neo-epidermis was not observed in control, while the FD samples induced neo-epidermis from the wound edge. Due to the absorption capacity of fluids of gelatin, it can prevent fluid accumulation from wounds. By absorbing excess exudate and cell debris from wounds, gelatin may improve wound healing [47]. HA affects the signaling of epidermal and dermal cells [48]. CD44, as HA receptor present on the surface of cell membranes, triggers differentiation in human keratinocytes and fibroblast cells [49-51]. Therefore, HA attached to wounds may bind to CD44 in epidermal or fibroblast cells and wound healing may be promoted by the signal transduction of CD44. In addition, it is known that CMCS accelerates granulation tissue formation by promoting the proliferation of fibroblasts and keratinocytes followed by wound healing acceleration [52]. Fibroblasts lead to the reorganization of extracellular matrix by the synthesis of structural proteins and secretion of cytokines [53]. Subsequently, CMCS diminishes scar formation by regulating collagen deposition from stimulating IL-8 in fibroblasts, TNF-a in macrophages and MMP-2 in wound skin.

On days 7 and 14, all slides exhibited wound healing phases, including the inflammatory and proliferative phases. A few inflammatory cells and granulation tissue formation were observed in all H\&E-stained images at a magnification of $\times 50$ (Day 7 and 14 of Figure 12. We found that FGF-7 noticeably accelerated re-epithelization. Furthermore, re-epithelization was distinctly observed in 2-GHC-FD-8/F1 6. After $21 \mathrm{~d}$, in all samples, inflammatory cells were decreased (Day 21 of Figure 12). In addition, bulbs, hair follicles, papillae, and sebaceous glands were confirmed in 2-GHC-FD-8/F2-3-treated wounds. In particular, among all samples, 2-GHC-FD-8/F3 showed the highest number of newly formed blood vessels, indicating its superior wound healing. These results indicate that FGF-7 concentrations less than $8.0 \times 10^{-11} \mathrm{M}$ can improve wound healing. Moreover, compared with the control, 2-GHC-FD-8/F3 resulted in a remarkable collagen deposition. Collagen formation in wounds is a very important point for wound remodeling and tensile strength of healed tissues [54]. MT stain was employed for investigating collagen formation in wounds after 7, 14, and 21 days of healing period (Figure 12). The collagen formation was observed in blue region in all samples (Figure 12). Compared with control, 2-GHC-FD-8-based samples displayed marked organed and numerous collagen formation. Furthermore, densely packed and parallel aligned mature collagen formation was observed in 2-GHC-FD-8-based samples.

During wound healing, macrophages play important roles in cleaning wounds and remodeling, including classical activation (M1 macrophages) and alternative activation (M2 macrophages). In the inflammatory phase (M1 macrophages) after wound production, neutrophils and monocytes rapidly migrate to the wound [55]. In addition, inflammatory cells release lysosomal enzymes, reactive oxygen species, and clean cell debris. Subsequently, wound healing moves to proliferation through inflammation. In the proliferative phase, M2 macrophages induce anti-inflammatory cytokines, such as IL-10, and then a decrease in inflammatory cells is observed. Wound healing includes the participation and coordination of growth factors and cytokines. FGF-7 is a growth factor that accelerates wound healing, and significantly stimulates the migration and proliferation of keratinocytes [20]. The expression of FGF-7 has been shown to be dramatically upregulated in full-thickness excisional wounds of mice and humans after skin injury [56]. It was also observed to increase the proliferation of basal keratinocytes and improve re-epithelialization $[57,58]$. Considering these results, we reasonably concluded that FGF-7 in 2-GHC-FD-8 leads to 
rapid wound development through the inflammatory phase, thereby accelerating wound healing.

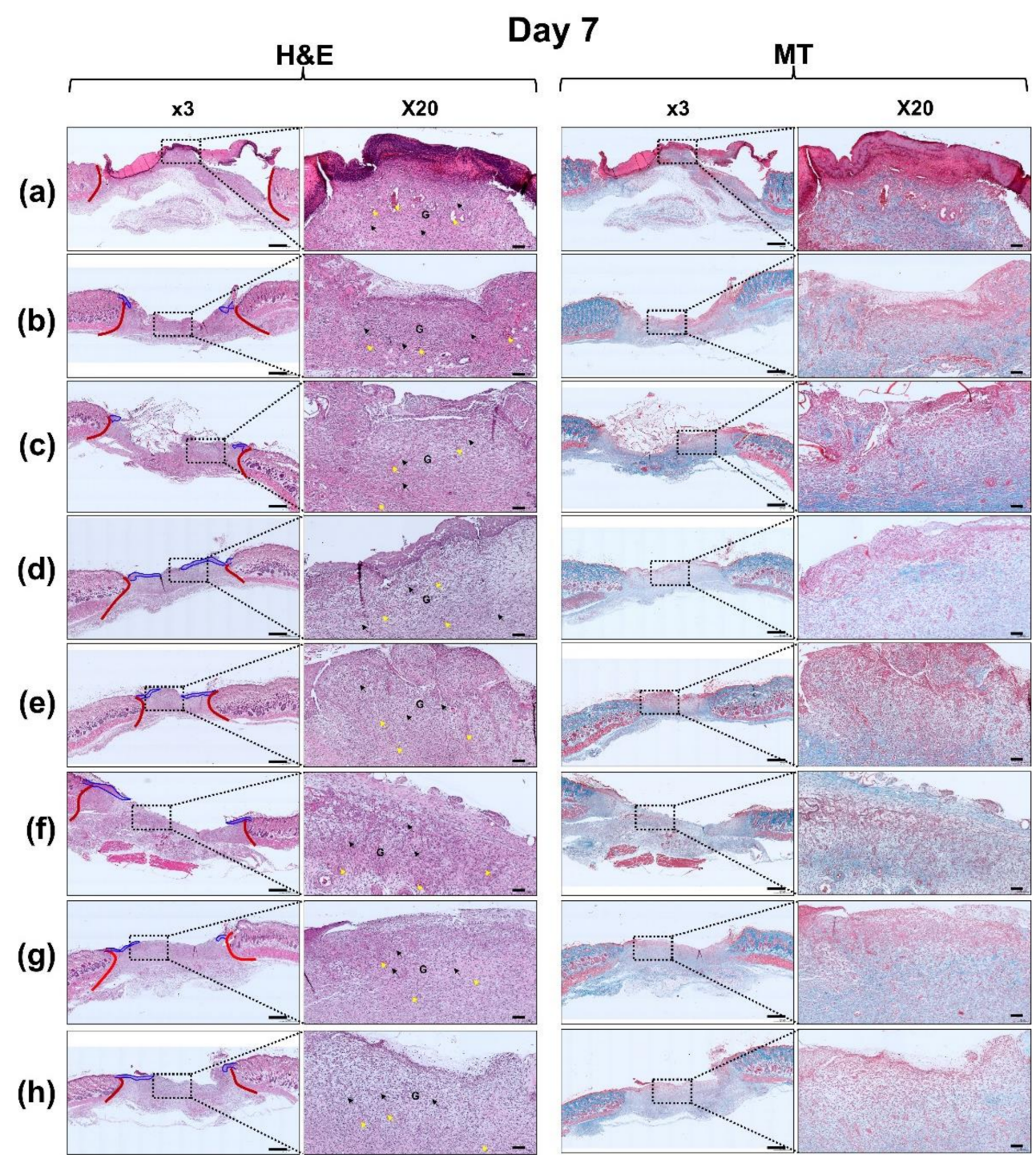

Figure 11. Cont. 


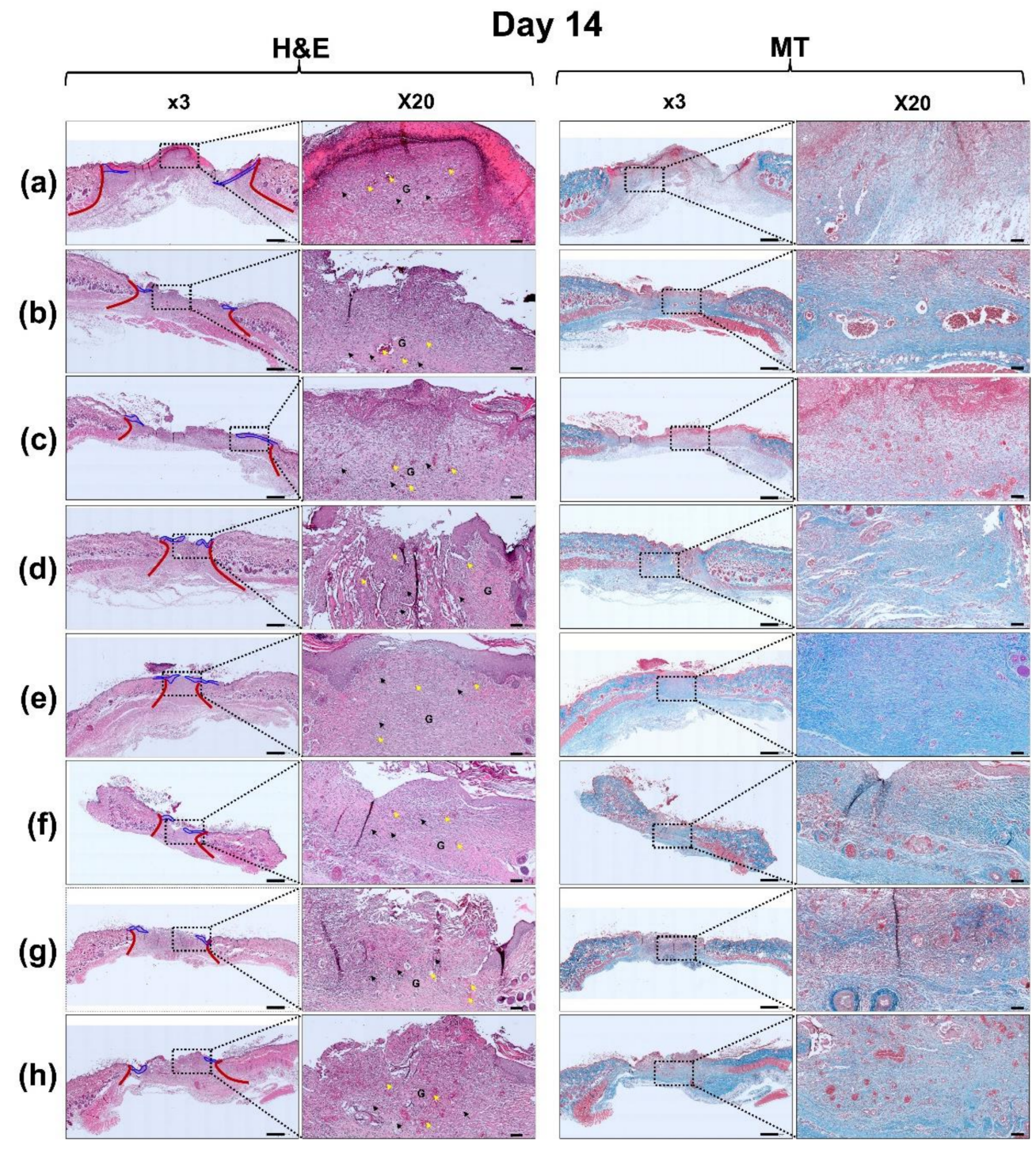

Figure 12. Cont. 


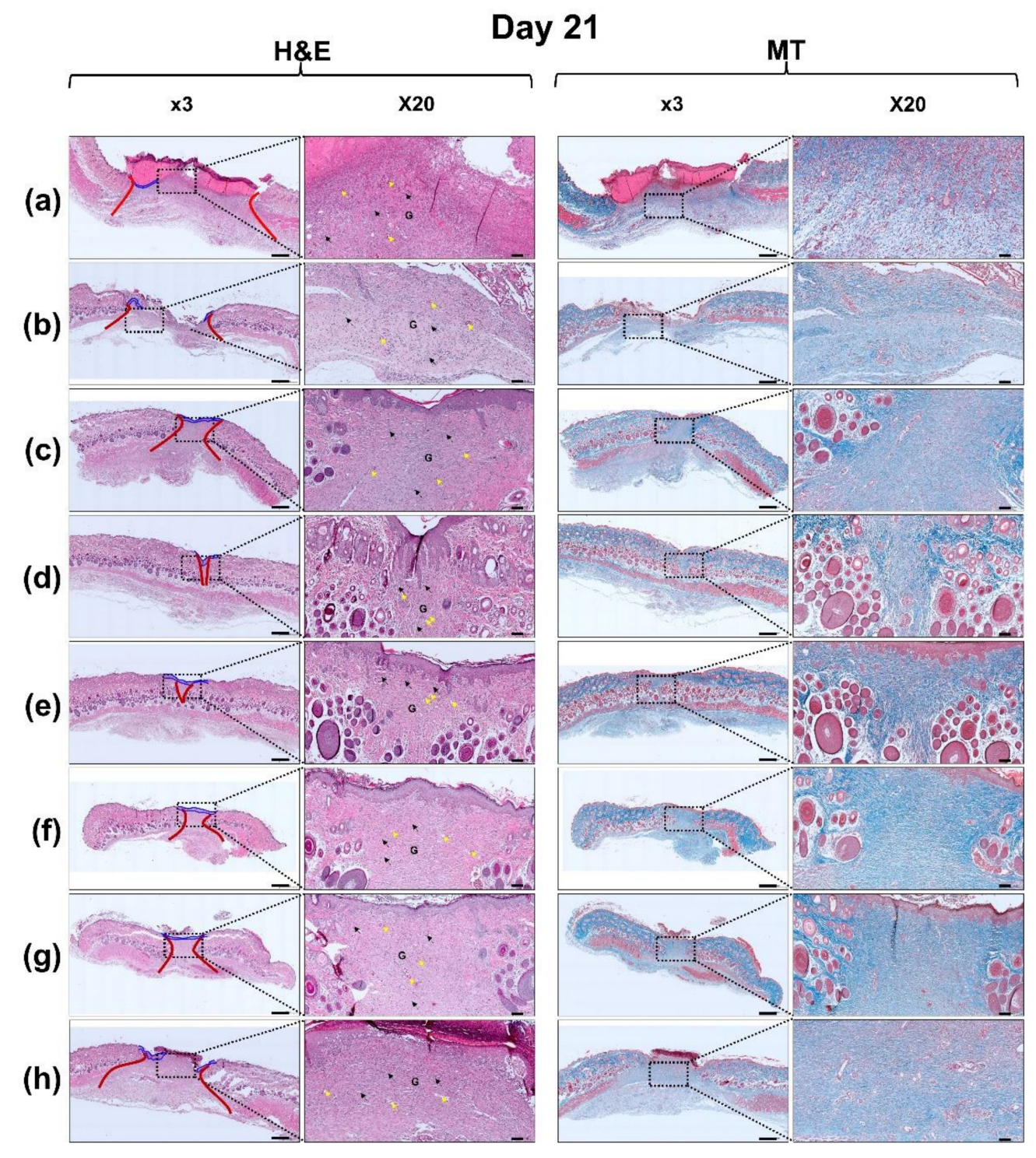

Figure 12. H\&E and MT stained slides of wounds treated with (a) 2-GHC-FD-8; (b) 2-GHC-FD-8/F1; (c) 2-GHC-FD-8/F2, (d) 2-GHC-FD-8/F3; (e) 2-GHC-FD-8/F4; (f) 2-GHC-FD-8/F5; (g) 2-GHC-FD8/F6; and (h) 2-GHC-FD-8/F7 for 7, 14, and 21 days. At slides at $\times 3$, red and blue lines indicate boundary between normal and newly formed tissues, and newly formed epithelial layer, respectively. At slides at $\times 20$, black and yellow arrows indicate inflammatory cells and newly formed blood vessels, respectively. G: granulation tissue.

\section{Conclusions}

Our study investigated the in vivo wound healing effect of FDs based on gelatin, HA, and CMCS containing FGF-7. 2-GHC-FD-8 composed of 2\% $(w / v)$ gelatin, $20 \% \mathrm{HA}$ $(w / w)$, and $50 \%(w / w)$ CMCS showed improved cell proliferation due to its appropriate interconnected porosity, tensile strength, and elongation. In addition, 2-GHC-FD-8/F3 containing $8.0 \times 10^{-11} \mathrm{M}$ of FGF-7 enhanced routine wound healing by inducing positive histological changes and collagen formation, which was evaluated by H\&E and MT staining. Gelatin, HA, CMCS, and FGF-7 have been investigated for wound healing; however, to our knowledge, this study is the first to evaluate wound healing in vivo. Although this research reports the potential of 2-GHC-FD-8-F3 on wound healing acceleration, further experiments need to be conducted, such as, FGF-7 activity, antibacterial activity, and extension of animal model for precise evaluation. In addition, larger sizes of wounds are recommended to evaluate the wound heling effect of 2-GHC-FD-8-F3. 
Author Contributions: Conceptualization, L.J., S.-J.Y. and D.H.Y.; methodology, L.J., S.-J.Y. and D.H.Y.; Investigation, D.H.L., Y.C.P., W.Y.K. and J.H.L.; Resources, S.-J.Y. and D.H.Y.; data curating, L.J., S.-J.Y. and D.H.Y.; writing-original draft preparation, L.J., S.-J.Y. and D.H.Y.; supervision, G.K. and H.J.C.; funding acquisition, S.-J.Y. and D.H.Y. All authors have read and agreed to the published version of the manuscript.

Funding: This research was supported by the Ministry of Trade, Industry \& Energy (MOTIE, Korea) (20003560, 20004627 and 20014222; D.H.Y.), the Technology development program (S2782460; D.H.Y.), by the Ministry of SMEs and Startups (MSS; Republic of Korea), and by the Fund of Chonbuk National University-Industrial Cooperation (No. 2101000448; S.-J.Y.).

Institutional Review Board Statement: The animal test was approved by the Institutional Animal Care and Use Committee of Chonbuk National University (23 March 2020; No: CBNU 2020-031).

Informed Consent Statement: Not applicable.

Data Availability Statement: The data in this study are available on request from the cor- responding author.

Conflicts of Interest: The authors declare no conflict of interest.

\section{References}

1. Junker, J.P.E.; Kamel, R.A.; Caterson, E.J.; Eriksson, E. Clinical impact upon wound healing and inflammation in moist, wet, and dry environments. Adv. Wound Care 2013, 2, 348-356. [CrossRef]

2. Dhivya, S.; Padma, V.; Santhini, E. Wound dressings-A review. Biomedicine 2015, 5, 22. [CrossRef]

3. Nielsen, J.; Fogh, K. Clinical utility of foam dressings in wound management: A review. Chronic Wound Care Manag. Res. 2015, 2, 31-38. [CrossRef]

4. Moura, L.I.F.; Dias, A.M.A.; Carvalho, E.; Sousa, H.C. Recent advances on the development of wound dressings for diabetic foot ulcer treatment-A review. Acta Biomater. 2013, 9, 7093-7114. [CrossRef] [PubMed]

5. Bay, M.Y.; Chen, M.C.; Yu, W.C.; Lin, J.Y. Foam dressing incorporating herbal extract: An all-natural dressing for potential use in wound healing. J. Bioact. Compat. Polym. Biomed. Appl. 2016, 32, 293-308. [CrossRef]

6. Mogosanu, G.D.; Grumezescu, A.M. Natural and synthetic polymers for wounds and burns dressing. Int. J. Pharm. 2014, 436, 127-136. [CrossRef] [PubMed]

7. Suarato, G.; Bertorelli, R.; Athanassiou, A. Borrowing from nature: Biopolymers and biocomposites as smart Wound care materials. Front. Bioeng. Biotech. 2018, 6, 1-11. [CrossRef]

8. Graca, M.F.P.; Miguel, S.P.; Cabral, C.S.D.; Correia, I.J. Hyaluronic acid-based wound dressings: A review. Carbohy. Polym. 2020, 241, 116364. [CrossRef]

9. Xu, W.; Wang, Z.; Liu, Y.; Wang, L.; Jiang, Z.; Li, T.; Zhang, W.; Liang, Y. Carboxymeyhyl chitosan/gelatin/hyaluronic acid blended-membranes as epithelia transplanting scaffold for corneal wound healing. Carbohy. Polym. 2018, 192, 240-250. [CrossRef]

10. Shariatinia, Z. Carboxymethyl chitosan: Properties and biomedical applications. Int. J. Biolog. Macromol. 2018, 120, 1406-1419. [CrossRef]

11. Hyun, H.; Park, M.H.; Jo, G.; Lee, B.Y.; Choi, J.W.; Chun, H.J.; Kim, H.S.; Yang, D.H. Injectable glycol chitosan hydrogel containing folic acid-functionalized cyclodextrin-paclitaxel complex for breast cancer therapy. Nanomaterials 2021, 11, 317. [CrossRef]

12. Moon, Y.J.; Yoon, S.-J.; Koo, J.-H.; Yoon, Y.; Byun, H.J.; Kim, H.S.; Khang, G.; Chun, H.J.; Yang, D.H. $\beta$-Cyclodextrin/triclosan complex-grafted maehacrylated glycol chitosan hydrogel by photocrosslinking via visible light irradiation for a tissue bioadhesive. Int. J. Mol. Sci. 2021, 22, 700. [CrossRef]

13. Hyun, H.; Park, M.H.; Jo, G.; Kim, S.Y.; Chun, H.J.; Yang, D.H. Photo-cured glycol chitosan hydrogel for ovarian cancer drug delivery. Mar. Drugs 2019, 17, 41. [CrossRef]

14. Seo, K.H.; You, S.J.; Chun, H.J.; Kim, C.; Lee, W.K.; Lim, Y.M.; Nho, Y.C.; Jang, J.W. In vitro and in vivo biocompatibility of $\gamma$-ray crosslinked gelatin-poly(vinyl alcohol) hydrogels. Tissue Eng. Regen. Med. 2009, 6, 414-418.

15. You, S.J.; Ahn, W.S.; Jang, H.S.; Kang, M.I.; Chun, H.J.; Lim, Y.M.; Nho, Y.C. Preparation and characterization of gelatin-poly(vinyl alcohol) hydrogels for three-dimensional cell culture. J. Ind. Eng. Chem. 2007, 13, 116-120.

16. Seo, N.M.; Ko, J.H.; Park, Y.H.; Chun, H.J. In vitro biocompatibility of PLGA-HA nano-hybrid scaffold. Tissue Eng. Regen. Med. 2011, 8, 16-22.

17. Park, J.W.; Hwang, S.R.; Yoon, I.S. Advanced growth factor delivery systems in wound management and skin regeneration. Molecules 2017, 22, 1259. [CrossRef]

18. Peng, C.; Chen, B.; Kao, H.K.; Murphy, G.; Orgill, D.; Guo, L. Lack of FGF-7 further delays cutaneous wound healing in diabetic mice. Plast. Reconstr. Surg. 2011, 128, 673-684. [CrossRef]

19. Finch, P.W.; Rubin, J.S.; Miki, T.; Ron, D.; Aaronson, S.A. Human KGF is FGF-related with properties of a paracrine effector of epithelial cell growth. Science 1989, 245, 752-755. [CrossRef]

20. Robert, G. Growth factors and chronic wound healing: Past, present, and future. Adv. Skin Wound Care 2004, 17, 24-35. [CrossRef] 
21. Yoon, S.-J.; Hyun, H.; Lee, D.-W.; Yang, D.H. Visible light-cured glycol chitosan hydrogel containing a beta-cyclodextrin-curcumin inclusion complex improves wound healing in vivo. Molecules 2017, 22, 1513. [CrossRef]

22. Andrgie, A.T.; Darge, H.F.; Mekonnen, T.W.; Birhan, Y.S.; Hanurry, E.Y.; Chou, H.-Y.; Wang, C.-F.; Tsai, H.-C.; Yang, J.M.; Chang, Y.-H. Ibuprofen-loade heparin modified thermosensitive hydrogel for inhibiting excessive inflammation and promoting wound healing. Polymers 2020, 12, 2619. [CrossRef] [PubMed]

23. Shin, D.Y.; Park, J.-U.; Choi, M.-H.; Kim, S.; Kim, H.-E.; Jeong, S.-H. Polydeoxyribonucleotide-delivering therapeutic hydrogel for diabetic wound healing. Sci. Rep. 2020, 10, 16811. [CrossRef] [PubMed]

24. Khunmanee, S.; Jeong, Y.H.; Park, H.S. Crosslinking method of hyaluronic-based hydrogel for biomedical applications. J. Tissue Eng. 2017, 8, 1-16. [CrossRef]

25. Nadieh, K.; Aliasghar, B.; Mohammad, T.K.; Masoud, M. Platelet-rich plasma-hyaluronic acid/chondroitin sulfate/carboxymethyl chitosan hydrogel for cartilage regeneration. Biotech. Appl. Biochem. 2021, 1-14. [CrossRef]

26. Cam, C.; Zhu, S.; Truong, N.F.; Scumpia, P.O.; Segura, T. Systematic evaluation of natural scaffolds in cutaneous wound healing. J. Mater. Chem. B 2015, 3, 7986-7992. [CrossRef]

27. Nagahama, H.; Divya Rani, V.V.; Shalumon, K.T.; Jayakumar, R.; Nair, S.V.; Koiwa, S.; Furuike, T.; Tamura, H. Preparation, characterization, bioactive and cell attachment studies of $\alpha$-chitin/gelatin composite membranes. Int. J. Biolog. Macromol. 2009, 44, 333-337. [CrossRef]

28. Davis, G.E. Affinity of integrins for damaged extracellular matrix: $\alpha_{v} \beta_{3}$ binds to denatured collagen type I through RGD sites. Biochem. Biophys. Res. Commun. 1992, 182, 1025-1031. [CrossRef]

29. Zhao, X.; Zhou, L.; Li, Q.; Zou, Q.; Du, C. Biomimetic mineralization of carboxymethyl chitosan nanofibers with improved osteogenic activity in vitro and in vivo. Carbohy. Polym. 2018, 195, 225-234. [CrossRef]

30. Lam, J.; Truong, N.F.; Segura, T. Design of cell-matrix interactions in hyaluronic acid hydrogel scaffolds. Acta Biomater. 2014, 10, 1571-1580. [CrossRef]

31. Elsner, J.J.; Zilberman, M. Novel antibiotic-eluting wound dressings: An in vitro study and engineering aspects in the dressing's design. J. Tissue Viability 2010, 19, 54-66. [CrossRef] [PubMed]

32. Zahouani, H.; Pailler-Mattei, C.; Sohm, B.; Vargiolu, R.; Cenizo, V.; Debret, R. Characterization of the mechanical properties of a dermal equivalent compared with human skin in vivo by indentation and static friction tests. Skin Res. Technol. 2009, 15, 68-76. [CrossRef]

33. Xu, R.; Xia, H.; He, W.; Li, Z.; Zhao, J.; Liu, B.; Wang, Y.; Lei, Q.; Kong, Y.; Bai, Y.; et al. Controlled water vapor transmission rate promotes wound-healing via wound re-epithelialization and contraction enhancement. Sci. Rep. 2016, 6, 24596. [CrossRef] [PubMed]

34. Lee, E.; Zhang, H.; Jackson, J.K.; Lim, C.J.; Chiao, M. Janus films with stretchable and waterproof properties for wound care and drug delivery applications. RSC Adv. 2016, 6, 79900-79909. [CrossRef]

35. Ekaterina, I.S.; Elena, D.N.; Olga, N.V.; Tatiana, G.V. Experimental wound dressings of degradable PHA for skin defect repair. J. Mater. Sci. Mater. Med. 2016, 27, 165. [CrossRef]

36. Kowalczuk, D.; Pitucha, M. Application of FTIR Method for the assessment of immobilization of active substances in the matrix of biomedical materials. Materials 2019, 12, 2972. [CrossRef]

37. Shi, G.; Cai, Q.; Wang, C.; Lu, N.; Wang, S.; Bei, J. Fabrication and biocompatibility of cell scaffolds of poly(L-lactic acid) and poly(L-lactic-co-glycolic acid). Polym. Adv. Technol. 2002, 13, 227-232. [CrossRef]

38. Frederic, R.; Sandra, H.; Jean-Marie, V.; Valerie, R.; Gaelle, L.R.; Norman, J.M.; Olivier, C.; Jean, F.; Philippe, B. FGF7/KGF triggers cell transformation and invasion on immortalized human prostatic epithelial PNT1A cells. Int. J. Cancer 1999, 82, 237-243. [CrossRef]

39. Jiao, J.; Peng, C.; Li, C.; Qi, Z.; Zhan, J.; Pan, S. Dual bio-active factors with adhesion function modified electrospun fibrous scaffold for skin wound and infections therapeutics. Sci. Rep. 2021, 11, 11-13. [CrossRef]

40. Park, J.P.; Lee, Y.M.; Lee, J.K.; Seol, Y.J.; Chung, C.P.; Lee, S.J. Controlled release of platelet-derived growth factor-BB from chondroitin sulfate-chitosan sponge for guided bone regeneration. J. Control Release 2000, 67, 385-394. [CrossRef]

41. Xizo, Z.; Zheng, X.; An, Y.; Wang, K.; Zhang, J.; He, H. Zwitterionic hydrogel for sustained release of growth factors to enhance wound healing. Biomater. Sci. 2021, 9, 882-891.

42. Lin, M.J.; Lu, M.C.; Chang, H.Y. Sustained Release of Insulin-Like Growth Factor-1 from Bombyx mori L. Silk Fibroin Delivery for Wound Therapy. Int. J. Mol. Sci. 2021, 22, 6267. [CrossRef]

43. Doi, H.; Kitajima, Y.; Luo, L.; Yang, C.; Tateishi, S.; Ono, Y.; Urata, Y.; Goto, S.; Mori, R.; Masuzaki, H.; et al. Potency of umbilical cord blood- and Wharton's jelly-derived mesenchymal stem cells for scarless wound healing. Sci. Rep. 2016, 6, 18844. [CrossRef]

44. Yang, D.H.; Seo, D.I.; Lee, D.-W.; Bhang, S.H.; Park, K.; Jang, G.; Kim, C.H.; Chun, H.J. Preparation and evaluation of visible-light cured glycol chitosan hydrogel dressing containing dual growth factors for accelerated wound healing. J. Ind. Eng. Chem. 2017, 53, 360-370. [CrossRef]

45. Rufaihah, A.J.; Huang, N.F.; Jamé, S.; Lee, J.C.; Nguyen, H.N.; Byers, B.; De, A.; Okogbaa, J.; Rollins, M.; Reijo-Pera, R.; et al. Endothelial cells derived from human iPSCS increase capillary density and improve perfusion in a mouse model of peripheral arterial disease. Arteriscler. Thromb. Vasc. Biol. 2011, 31, e72-e79. [CrossRef]

46. Gillitzer, R.; Goebeler, M. Chemokines in cutaneous wound healing. J. Leukoc. Biol. 2001, 69, 513-521. [CrossRef] 
47. Ulubayram, K.; Cakar, A.N.; Korkusuz, P.; Ertan, C.; Hasirci, N. EGF containing gelatin-based wound dressings. Biomaterials 2001, 22, 1345-1356. [CrossRef]

48. Kawano, Y.; Patrulea, V.; Sublet, E.; Borchard, G.; Iyoda, T.; Kageyama, R.; Morita, A.; Seino, S.; Yoshida, H.; Jordan, O.; et al. Wound healing promotion by hyaluronic acid: Effect of molecular weight on gene expression and in vivo wound closure. Phamaceuticals 2021, 14, 301. [CrossRef]

49. Yang, C.; Cao, M.; Liu, H.; He, Y.; Xu, J.; Du, Y.; Liu, Y.; Wang, W.; Cui, L.; Hu, J.; et al. The high and low molecular weight forms of hyaluronan have distinct effects on CD44 clustering. J. Biol. Chem. 2012, 287, 43094-43107. [CrossRef]

50. Wang, Y.; Mack, J.A.; Maytin, E.V. CD44 inhibits $\alpha$-SMA gene expression via a novel G-actin/MRTF-mediated pathway that intersects with TGF $\beta R /$ p38MAPK signaling in murine skin fibroblasts. J. Biol. Chem. 2019, 294, 12779-12794. [CrossRef]

51. Bourguignon, L.Y.W.; Ramez, M.; Gilad, E.; Singleton, P.A.; Man, M.-Q.; Crumrine, D.A.; Elias, P.M.; Feingold, K.R. HyauronanCD44 interaction stimulates keratinocyte differentiation, lamellar body formation/secretion, and permeability barrier homeostasis. J. Investig. Dermatol. 2006, 126, 1356-1365. [CrossRef] [PubMed]

52. Chen, X.G.; Wang, Z.; Liu, W.S.; Park, H.J. The effect of carboxymethyl-chitosan on proliferation and collagen secretion of normal and keloid skin fibroblasts. Biomaterials 2002, 23, 4609-4614. [CrossRef]

53. Werner, S.; Grose, R. Regulation of wound healing by growth factors and cytokines. Physiol. Rev. 2003, 83, 835-870. [CrossRef]

54. Li, X.; Nan, K.; Li, L.; Zhang, Z.; Chen, H. In vivo evaluation of curcumin nanoformulation loaded methoxy poly(ethylene glycol)-graft-chitosan composite film for wound healing application. Carbohy. Polym. 2012, 88, 84-90. [CrossRef]

55. Landen, N.X.; Li, D.; Stahle, M. Transition from inflammation to proliferation: A critical step during wound healing. Cell. Mol. Life Sci. 2016, 73, 3861-3885. [CrossRef] [PubMed]

56. Liancu, W.; Glenn, F.P.; Robert, D.G.; Thomas, A.M. Keratinocyte growth factor induces granulation tissue in ischemic dermal wounds. Arch. Surg. 1996, 131, 660. [CrossRef]

57. Danilenko, D.M.; Ring, B.D.; Tarpley, J.E.; Morris, B.; Van, G.Y.; Morawiecki, A.; Callahan, W.; Goldenberg, M.; Hershenson, S.; Pierce, G.F. Differing targets and effects of keratinocyte growth factor, platelet-derived growth factor-BB, epidermal growth factor, and neu differentiation factor. Am. J. Pathol. 1995, 147, 1261-1277.

58. Guo, L.; Yu, Q.C.; Fuchs, E. Targeting expression of keratinocyte growth factor to keratinocytes elicits striking changes in epithelial differentiation in transgenic mice. EMBO J. 1993, 12, 973-986. [CrossRef] 